\title{
La imputabilidad en la responsabilidad patrimonial del Estado en las denominadas ejecuciones extrajudiciales y la derivada para los agentes públicos
}

Imputability in the patrimonial responsibility of the State in the so-called extrajudicial executions and the subsequent for public agents

\author{
Imputabilidade na responsabilidade patrimonial do Estado \\ nas chamadas execuções extrajudiciais e posteriores para \\ agentes públicos
}

\section{Fernando Yepes Gómez ${ }^{1}$}

Recibido: 12 de agosto de 2020 Aprobado: 26 de septiembre 2020

Publicado: 12 de enero de 2021

Cómo citar este artículo: Fernando Yepes Gómez. La imputabilidad en la responsabilidad patrimonial del Estado en las denominadas ejecuciones extrajudiciales y la derivada para los agentes públicos. DIXI

Artículo de investigación. https://doi.org/10.16925/2357-5891.2021.01.03

1 Maestría en Derecho Administrativo, Universidad Libre, Seccional Cali, Especialización Argumentación Jurídica U. Autónoma de Occidente, Especialización Contratación Estatal, U Externado de Colombia, Especialización Derecho Administrativo, U. Pontificia Bolivariana, Abogado, U. San Buenaventura Cali.

Correo electrónico: fernandoyepes@yepesgomezabogados.com, feyego@yahoo.com. ORCID: https://orcid.org/0000-0003-2192-6884 
2 La imputabilidad en la responsabilidad patrimonial del Estado en las denominadas ejecuciones extrajudiciales y la derivada para los agentes públicos

\section{Resumen}

Tema y alcance: las últimas décadas de la historia en Colombia han estado marcadas por el profundo perjuicio de los actos de violencia de grupos subversivos. La reacción del Estado no se ha hecho esperar y en el afán de mejorar los resultados frente a las actividades de los integrantes de los grupos al margen de ley, ha propuesto gran variedad de políticas a los miembros de la Fuerza Pública para estimular o incentivar su valiosa actuación.

Características: primero a finales de la década de los setenta y después en la primera década del siglo XXI, se generalizaron prácticas (eso sí, denunciadas interna y externamente) que consistían en conducir a las víctimas con el apoyo de civiles informantes para simular combates o atribuirles la comisión de delitos, a fin de obtener privilegios económicos e institucionales por su muerte. Esto resultó en la constitución de prácticas criminales con el velo de jurídicas y legales (ejecuciones extrajudiciales) para mostrar eficacia y eficiencia.

Hallazgos: el análisis de la responsabilidad del Estado por las ejecuciones extrajudiciales en Colombia ha sido objeto del análisis tanto del máximo tribunal de lo contencioso administrativo, como de la Corte Interamericana de Derechos Humanos y ha descansado sobre la idea de que la imputabilidad jurídica no entraña discusión.

Conclusión: el menoscabo y la vulneración de derechos fundamentales de los colombianos no podía inferir otro juicio de reproche al Estado que el de declarar su deber indemnizatorio frente a las víctimas, dadas las turbadoras notas luctuosas que empañan además la credibilidad en la Fuerza Pública, pues si su misión y función es la de garantizar o salvaguardar los derechos del Estado, el hecho de convertirse en el artífice y promotor de esas trasgresiones deja un manto de desconfianza en su labor, y hay translocación de posiciones de asegurador a infractor.

Palabras clave: responsabilidad patrimonial, ejecución extrajudicial, falso positivo, imputabilidad jurídica, causalidad, responsabilidad personal del agente, acto del servicio.

\section{Abstract}

Subject and scope: the last decades of Colombian history have been marked by the profound damage caused by acts of violence from subversive groups. The State's reaction has not been long in coming, and to improve the results in fighting the members of the illegal groups, it has proposed a great variety of policies to the members of the Public Force to stimulate or encourage their performance.

Characteristics: first, at the end of the seventies and, later, in the first decade of the xxi century, practices that consisted of leading victims, with the support of civilian informants to simulate combats or attribute the commission of crimes to them, became widespread (indeed reported internally and externally) to obtain economic and institutional privileges for their death. This resulted in the constitution of criminal practices with the disguise of being legal (extrajudicial executions) to show efficacy and efficiency.

Findings: the analysis of the State's responsibility for extrajudicial executions in Colombia has been the subject of analysis by both the highest Administrative Contentious Court and the Inter-American Court of Human Rights and has rested on the idea that legal accountability does not entail discussion.

Conclusion: the violation of Colombian's fundamental rights could not infer another judgment of disapproval to the State than that of declaring its duty to compensate the victims, given the disturbing notes of distress that also tarnish the credibility of the Public Force, since if their mission and function is to guarantee or safeguard the rights of the State, the fact of becoming the architect and promoter of these transgressions leaves a cloak of mistrust in their work, and there is a translocation of positions from insurer to infringer.

Keywords: Patrimonial Responsibility, Extrajudicial Execution, False Positive, Legal Imputability, Causality, Agent Personal Imputability, Act of Service. 


\section{Resumo}

Tema e alcance: as últimas décadas da história colombiana foram marcadas pelos profundos danos causados por atos de violência de grupos subversivos. A reação do Estado não tardou a chegar e, para melhorar os resultados no combate aos integrantes dos grupos ilegais, propôs uma grande variedade de políticas aos integrantes da Força Pública para estimular ou estimular sua atuação.

Características: primeiro, no final dos anos setenta e, posteriormente, na primeira década do século XXI, generalizaram-se práticas que consistiam em liderar vítimas, com o apoio de informantes civis para simular combates ou atribuir-Ihes o cometimento de crimes (na verdade, relatado interna e externamente) para obter privilégios econômicos e institucionais por sua morte. Isso resultou na constituição de práticas criminosas com o disfarce de legal (execuções extrajudiciais) para demonstrar eficácia e eficiência.

Conclusões: a análise da responsabilidade do Estado pelas execuções extrajudiciais na Colômbia foi objeto de análise tanto do mais alto Tribunal Administrativo de Contencioso como da Corte Interamericana de Direitos Humanos e se baseou na ideia de que a responsabilização judicial não implica discussão.

Conclusão: a violação dos direitos fundamentais colombianos não poderia inferir outro juízo de desaprovação ao Estado que não o de declarar seu dever de indenizar as vítimas, dadas as inquietantes notas de angústia que também mancham a credibilidade da Força Pública, pois se sua missão e função é garantir ou salvaguardar os direitos do Estado, o facto de se tornar arquitecto e promotor destas transgressões deixa um manto de desconfiança na sua obra, havendo uma translocação de cargos de segurador para infractor.

Palavras-chave: Responsabilidade Patrimonial, Execução Extrajudicial, Falso Positivo, Imputabilidade Legal, Causalidade, Imputabilidade Pessoal do Agente, Ato de Prestação de Serviços.

\section{INTRODUCCIÓN}

Las últimas décadas de la historia en Colombia han estado marcadas por el profundo azote de los actos de violencia de grupos subversivos ${ }^{1}$. La reacción del Estado no se ha hecho esperar, y el afán de mejorar los resultados frente a las actividades de los integrantes de los grupos al margen de ley ha llevado a proponer gran variedad de políticas a los miembros de la Fuerza Pública para estimular o incentivar su valiosa actuación. No obstante, se han generalizado prácticas, eso sí denunciadas interna y externamente ${ }^{2}$, consistentes en conducir a las víctimas con el apoyo de civiles informantes para simular combates o atribuirles la comisión de delitos, con el fin de obtener privilegios económicos e institucionales por su muerte. Lo anterior resultó en la constitución de prácticas criminales con el velo de jurídicas y legales para mostrar eficacia y eficiencia.

1 Alberto Valencia Gutiérrez. VIOLENCIA EN COLOMBIA: AÑOS OCHENTA Y REFORMA CONSTITUCIONAL. Editorial Universidad del Valle. (1998). Pág. 39.

2 Ver: (i) Informe del 24 de febrero de 2011 de la Oficina del Alto Comisionado de la onU para los Derechos Humanos. Disponible en: http://ww.hchr.org.co; (ii) Informe de junio de 2010, Relatoría de la Organización de las Naciones Unidas, del Observatorio para la Protección de los Defensores de Derechos Humanos, programa conjunto de la Federación Internacional de Derechos Humanos (FIDH) y de la Organización Mundial contra la Tortura. Disponible en: http://www.un.org; (iii) Quinto informe, año 2008, de Amnistía Internacional. Disponible en: http://www.amnesty.org/es/human-rights. 
El menoscabo y la vulneración de los derechos fundamentales de los colombianos no podía inferir otro juicio de reproche al Estado que el de declarar su deber indemnizatorio frente a las víctimas, dadas las turbadoras notas luctuosas que empañan además la credibilidad en la Fuerza Pública, pues si su misión y función es la de garantizar o salvaguardar los derechos del Estado, el hecho de convertirse en el artífice y promotor de esas trasgresiones deja un manto de desconfianza en su labor, y hay translocación de posiciones de asegurador a infractor.

La responsabilidad del Estado por los daños causados a los asociados ha tenido una juiciosa evolución a partir de la interpretación del artículo 16 de la Constitución Política de $1886^{3}$, influenciada por la jurisprudencia y doctrina francesa ${ }^{4}$ y española ${ }^{5}$, que permitió en su momento definir caracteres especiales para estructurar la responsabilidad patrimonial de las instituciones públicas y que marcó un panorama diferente a la responsabilidad civil patrimonial, contemplado en la legislación civil. Y es que, como lo anota Josserand", "la historia de la responsabilidad es la historia y es el triunfo de la jurisprudencia, y también, en ciertas medidas, de la doctrina. En términos más generales, es el triunfo del espíritu, del sentido jurídico [...] Los jueces han sido el alma del progreso jurídico, los artífices laboriosos del derecho nuevo contra las fórmulas caducas del derecho tradicional".

La construcción de parámetros diferenciadores introdujo aspectos que permitían establecer una despejada divergencia entre la responsabilidad personal del servidor público y la responsabilidad de la entidad estatal. Es así como se incorporaron conceptos como el daño antijurídico 7 y el de imputabilidad. La Carta Política de 1991 produjo la "constitucionalización" de la responsabilidad del Estado y se erigió

3 La Carta Política de 1886 no insertó contenido normativo que pudiera servir como base o fundamento general a la obligación del Estado de indemnizar los perjuicios que causara con su actividad o que se produjeran con ocasión de esta, lo cual determinó un invaluable esfuerzo jurisprudencial que finalmente logró la autonomía de esta institución respecto a la equivalente existente en el derecho privado en relación con los daños ocasionados entre particulares, dotándola de reglas propias extraídas, fundamentalmente, de los principios de la misma Carta de 1886.

Por ejemplo, el profesor Michel Paillet y Louis Josserand.

5 Entre otros, Ricardo de Ángel Yagüez y Eduardo García De Enterría.

6 Louis Josserand. DERECHO CIVIL. TOMO II. Bosch. (1950). Pág. 344.

7 Mediante la Constitución Política de 1991, se acuña en nuestra sociedad jurídica un nuevo criterio de definición de la responsabilidad del Estado bajo el concepto de daño antijurídico. Así como la teoría de la culpa o falla del servicio tenía su fundamento en el Derecho francés, la tesis del daño antijurídico constituye una figura originaria del derecho español, cuyo soporte constitucional está plasmado en el artículo 106 de la Constitución de dicho país. En nuestro caso, la antijuridicidad del daño como criterio para establecer la responsabilidad del Estado colombiano tiene su fundamento en al artículo 90 de la Constitución Política. 
como garantía de los derechos e intereses de los administrados y de su patrimonio, ya que la responsabilidad patrimonial del Estado en ordenamiento jurídico tiene como fundamento un principio de garantía integral del patrimonio de los ciudadanos. Súmese que con el nuevo modelo estatal, el Estado social de derecho, se presentan dos grandes axiomas fundantes: el principio de legalidad y la responsabilidad patrimonial del Estado. La garantía de los derechos y las libertades de los ciudadanos no se preserva solamente con la exigencia a las autoridades públicas que en sus actuaciones se sujeten a la ley, sino que también es esencial que si el Estado en ejercicio de sus poderes de intervención causa un daño antijurídico o lesión, lo repare íntegramente . $^{2}$

El Consejo de Estado empezó a construir el concepto, ya con la innovación constitucional:

Es verdad que la Ley de Leyes no define el concepto de daño antijurídico, realidad que lleva a indagar el alcance actual del mismo. Y es la doctrina española la que lo precisa en todo su universo. Para Leguina, "un daño será antijurídico cuando la víctima del mismo no esté obligada por imperativo explícito del ordenamiento a soportar la lesión de un interés patrimonial garantizado por la norma jurídica [...] La ratio legis verdadera consiste en que cualquier particular, por el solo hecho de haber entrado en la obligada esfera de actuación administrativa que el principio de soberanía comporte, quedando subordinado a ella sin un deber expreso de sacrificio, siempre que haya sufrido un daño o sacrificio que reúna las condiciones de [injusto, efectivo, económicamente evaluable y susceptible de individualización personal o grupal], ha de tener la garantía por parte de la administración de su resarcimiento, dotándole de acción procesal directa contra la misma, sin que sea para ello preciso identificar si en el mencionado actuar lesionante hubo comportamiento voluntario, doloso o culposo, de la persona o personas que encarnan el órgano administrativo que lo produjo, máxime cuando el daño o perjuicio hubiera sido originado por un comportamiento institucional [...] Dentro de este universo constitucional no hay duda de que el fundamento de la responsabilidad administrativa no se da siempre por una conducta dolosa o culpable, que debe ser sancionada, sino por el quebranto patrimonial

8 Corte Constitucional de Colombia. SENTENCIA C-832 de 2001. (M,P. Rodrigo Escobar Gil; 8 de agosto de 2001). Demanda de inconstitucionalidad parcial contra el numeral 9 del artículo 136 del Código Contencioso Administrativo, modificado por el artículo 44 de la Ley 446 de 1998. 
6 La imputabilidad en la responsabilidad patrimonial del Estado en las denominadas ejecuciones extrajudiciales y la derivada para los agentes públicos

que hay que reparar [...] Por ello importa más reparar el daño causado que castigar una acción u omisión administrativa culpable. La finalidad de la responsabilidad patrimonial no consiste, pues, en borrar una culpa, sino en hacer recaer sobre el patrimonio de la administración, el daño sufrido por el particular". ${ }^{9}$

Tal orientación surgió a partir de las diferentes ponencias presentadas en la Asamblea Nacional Constituyente en relación con el tema. En la que se presentó para primer debate, se sostuvo:

Por otra parte, conviene que el régimen que se propone en materia de responsabilidad patrimonial del Estado no se limite a su mera consagración expresa a nivel constitucional, sino que, además, incorpore los más modernos criterios sobre la materia, consistentes en radicar el fundamento de esa responsabilidad en el daño antijurídico y en su imputabilidad al órgano estatal. De esta manera se resuelve el problema que hoy ya plantea la evidente insuficiencia del criterio de la llamada "falla del servicio público", dentro del cual no caben todas las actuales formas y casos de responsabilidad patrimonial, tales como el de la "responsabilidad por daño especial". En otras palabras, se desplaza el soporte de la responsabilidad administrativa, del concepto subjetivo de la antijuridicidad de la acción del Estado al concepto objetivo de la antijuridicidad habrá de predicarse cuando se cause un detrimento patrimonial que carezca de título jurídico válido y que exceda el conjunto de las cargas que normalmente debe soportar el individuo en su vida social. ${ }^{10}$

Lo anterior quiere decir que tiene como cimiento el daño ocasionado a la víctima, que pasó a ser el elemento más importante de la responsabilidad patrimonial estatal.

La mayor parte de las situaciones ocurridas con reiteración durante estos últimos años ha dado lugar a las censuras de responsabilidad patrimonial no solo ante los estamentos internos, sino también ante órganos internacionales como la Corte Interamericana de Derechos Humanos; en ambas jurisdicciones, el soporte de la obligación indemnizatoria declarada descansa en el supuesto de la obligación del

9 Consejo de Estado, Sala de lo Contencioso Administrativo, Sección Tercera. Sentencia del 22 de noviembre de 1991. Consejero ponente: Julio César Uribe Acosta.

10 Corte Constitucional de Colombia. Gaceta Constitucional N. ${ }^{\circ} 56$ del 22 de abril de 1991. 
"Estado" como ente garantista del respeto por los derechos humanos"1. Así, la omisión y la acción ilícita de sus componentes en desarrollo de los actos conocidos como "falsos positivos" o "ejecuciones extrajudiciales" comprometen a la entidad estatal por la relación causal en que se desenvuelve cada suceso atroz de su agente, que en desarrollo aparente del servicio público envuelve una actividad delictiva que procura solo la obtención de un interés personal.

El Consejo de Estado ha delimitado, a partir del contenido del artículo 90 de la Constitución Política de 1991, una teoría de la responsabilidad patrimonial de la administración pública que ha permitido cierto pacifismo académico, aunque sin que pueda desertarse la discusión propia de cualquier evento con trascendencia jurídica, y que se hace necesaria para enriquecer la órbita académica, pues esta área del derecho no solo involucra estudios desde el frío plano de la licitud, legalidad o legitimidad, sino que además se observan componentes de orden constitucional y supraconstitucional, en los que el talante del derecho conculcado, y la anteposición de principios y valores constitucionales juegan un papel relevante para impulsar la decisión jurisdiccional de reproche patrimonial. Sin embargo, el tema no puede ser ajeno a la constante revaluación de conceptos, producto de la concepción y orientación filosófica del operador jurídico de turno, que introduce o resta elementos a una teoría, o simplemente para dar suficiente argumentación a su posición, como ha ocurrido con la introducción del denominado "daño a la salud" como una postura renovadora frente a la multiplicidad de perjuicios inmateriales que se venían planteando por los operadores ${ }^{12}$.

El examen de la responsabilidad en los eventos que tratan este escrito forja un análisis teórico-jurídico desde el elemento "imputabilidad" para llegar a identificar el tipo de responsabilidad del servidor público comprometido, en especial lo que surge frente al administrado, y si ella termina, en realidad, comprometiendo la de la institución pública. Uniformes y claros han sido los precedentes del Alto Tribunal de lo Contencioso Administrativo, que no todo acto de un servidor público compromete necesariamente la actividad de la administración pública ${ }^{13}$, pues para ello deberá tenerse en cuenta si guarda "relación con el servicio o no", o si fue "con causa o con

11 Corte Interamericana de Derechos Humanos. Sentencia del 12 de septiembre de 2005. Caso Gutiérrez Soler vs. Colombia. Juez: Antônio Cançado Trindade. Disponible en: www.corteidh.or.cr/docs/casos/articulos /seriec_132_esp.pdf

12 Consejo de Estado, Sala de lo Contencioso Administrativo, Sección Tercera. Sentencia del 14 de septiembre de 2011. Consejero ponente: Enrique Gil Botero. Radicación 05001-23-25-000-1994-00020-01(19031). Actor: Antonio José Vigoya Giraldo y otros.

13 Consejo de Estado, Sala de lo Contencioso Administrativo, Sección Tercera. Sentencia del 28 de abril de 2010. Consejera ponente: Ruth Stella Correa Palacio. Radicación 76001-23-31-000-1995-01581-01(17201). Actor: Yasmín Millán Dávila y otros. Demandado: Nación-Ministerio de Defensa-Policía Nacional. 
ocasión del mismo", para delimitar la responsabilidad de la institución en la denominada falta personal sin atribución al servicio. No obstante, se presentan eventos en que la apariencia de la ejecución de una misión o una labor pública habrá de servir de telón del acto que se ejecuta con un interés subjetivo en el que el servicio público no ronda la intención del servidor.

En las voceadas, en forma irregular, "ejecuciones extrajudiciales"14, se encuentra con frecuencia que el primer cuestionamiento en el juicio punitivo es la verificación de la correspondencia entre el acto ilícito y el ejercicio propio de la función militar a fin de determinar el funcionario judicial competente para la investigación y juzgamiento de la ilicitud. Por ejemplo, al respecto el Código Penal Militar vigente ${ }^{15}$ sostiene en el inicio de su articulado que "de los delitos cometidos por los miembros de la Fuerza Pública en servicio activo, y en relación con el mismo servicio, conocerán las Cortes Marciales o los Tribunales Militares, con arreglo a las disposiciones de este Código. Tales Cortes o Tribunales estarán integrados por miembros de la Fuerza Pública en servicio activo o en retiro"; y después dispone que "son delitos relacionados con el servicio aquellos cometidos por los miembros de la Fuerza Pública en servicio activo dentro o fuera del territorio nacional, cuando los mismos se deriven directamente de la función militar o policial que la Constitución, la ley y los reglamentos les ha asignado", para luego identificar que no están relacionados con el servicio en ningún caso "los delitos de tortura, genocidio, desaparición forzada, de lesa humanidad o aquellos que atenten contra el Derecho Internacional Humanitario entendidos en los términos definidos en convenios y tratados internacionales ratificados por Colombia, ni las conductas que sean abiertamente contrarias a la función constitucional de la Fuerza Pública y que por su sola comisión rompan el nexo funcional del agente con el servicio".

La configuración de que trataba la Ley 522 de 1999 se mantuvo, pero difería en el llano ámbito de aplicación que en su momento señalaba el Decreto 2550 de 1988, Código Penal Militar vigente al momento de la expedición de la Constitución Política de 1991; señalaba que se aplicarían dichas normas "a los militares en servicio activo que cometan hecho punible militar o común relacionado con el mismo servicio, dentro o fuera del territorio nacional, salvo las excepciones consagradas en el derecho internacional. También se aplicarán a los oficiales, suboficiales, y agentes de la Policía

14 La literalidad de la denominación pareciera dar a entender que existiera en Colombia legitimidad, y por orden judicial, de la ejecución de un ciudadano o administrado. La normatividad punitiva del Estado no contempla ninguna posibilidad de una ejecución o de un homicidio legítimo.

15 Congreso de la República de Colombia. LEY 1407 DE 2010. Por la cual se expide el Código Penal Militar. 17 de agosto de 2010. Do N. ${ }^{\circ} 47.804$. 
Nacional"16, quedando a criterio del juzgador identificar cuándo existía relación o no con el servicio.

La figura legislativa no fue solo producto de la reflexión y el análisis de la responsabilidad patrimonial de la administración. Estos cambios han obedecido a la adecuación del régimen jurídico interno gracias a las recomendaciones de la Comisión Interamericana de Derechos Humanos (CIDH) ${ }^{17}$, encontrando antecedentes en los que, a raíz de algunos episodios, se pidió que se excluyera "a la Policía colombiana de la jurisdicción militar como se establece parcialmente bajo la nueva Constitución colombiana. La jurisdicción militar debería excluir actos de tortura, ejecución extrajudicial y desaparición forzada, y estos delitos deberían estar sometidos a la jurisdicción de los tribunales civiles"18. Sin embargo, el objetivo fijado es lograr una investigación penal imparcial de los hechos y que permita a los familiares de las víctimas participar con uso pleno de sus prerrogativas en los procesos penales ante los tribunales militares, pues lastimosamente los resultados de la jurisdicción penal militar sobresalen por el alto grado de impunidad en sus investigaciones ${ }^{19}$ y por la negación al acceso al instructivo por parte de las víctimas y afectados.

La misma CIDH reiteró, en el Informe 26 del 30 de septiembre de 1997, la sugerencia al Estado colombiano de adoptar "los cambios en la Constitución, legislación o jurisprudencia que sean necesarios para que los delitos de tortura, ejecución extrajudicial y desaparición forzada cometidos por la Policía colombiana estén, en este tipo de casos, sujetos a la jurisdicción ordinaria"20. A su vez, pidió iniciar "las acciones que sean necesarias, de acuerdo con el ordenamiento jurídico vigente, para permitir la investigación y sanción penal de los responsables. Esto debe incluir una investigación

16 Congreso de la República de Colombia. LEY 522 DE 1991. Por la cual se expide el Código Penal Militar. 12 de agosto de 1991. Do N. 43.665. Artículo 14.

17 A pesar el término "recomendaciones" usado por la Convención Americana, debe ser interpretado conforme a su sentido corriente de acuerdo con la regla general de interpretación contenida en el artículo 31.1 de la Convención de Viena sobre el Derecho de los Tratados; por ello, no tiene el carácter de una decisión jurisdiccional obligatoria cuyo incumplimiento generaría la responsabilidad del Estado.

18 Por ejemplo, Informe $\mathrm{N}^{\circ} 50$ de 1996, aprobado por la Comisión Interamericana de Derechos Humanos en su 93. Periodo Ordinario de Sesiones.

19 Informe de la Misión a Colombia presentado a la Asamblea General de las Naciones Unidas por el Relator Especial sobre las ejecuciones extrajudiciales, sumarias o arbitrarias, Philip Alston. Marzo 31 de 2010, párr. 10 y 11. Respecto a la ausencia de denuncias e investigaciones, el informe del relator Alston indicó: "29. La falta de atribución de la responsabilidad penal ha sido un factor clave para que sigan produciéndose casos de falsos positivos. La tasa de impunidad de los homicidios atribuidos a las fuerzas de seguridad se estima actualmente en la alarmante cifra del 98,5\%. 24. Simplemente, los soldados sabían que podían cometer tales actos y salir impunes". Dentro del caso 11.142. Peticionario: Arturo Ribón vs. Colombia. 
seria, imparcial y completa terminando en un recuento oficial, adoptado por el Estado, donde se expondrá una versión correcta y completa de los hechos".

El legislador colombiano, en los estatutos punitivos de la Fuerza Pública de los años 1999 y 2010, reguló de manera literal la recomendación. La nueva regla jurídica puede admirarse no solo como el compromiso estatal por el respeto a los derechos humanos y el acatamiento de las normas de tratados internacionales ${ }^{21}$, sino también como la consecuencia del reconocimiento de la actuación ilícita y deliberadamente inconexa con la misión militar o policiva. Aquellas posturas están recogidas en las disposiciones normativas como las leyes 522 de 1999 y 1407 de 2010, en sus primeros artículos, que readecuaron el ámbito de aplicación de que trataba en el antiquísimo Decreto 250 de 1958 y el Decreto 2550 de 1998; Ilama a recapacitar sobre la relación jurídica entre el acto y el servicio como presupuesto de la imputabilidad jurídica, soporte del juicio indemnizatorio que adelanta con frecuencia la jurisdicción contenciosa administrativa y la Corte Interamericana de Derechos Humanos, sin que esto implique, se aclara, el menoscabo del derecho de la víctima y sus familiares a ser resarcidos.

El desarrollo de esta investigación llama a la atención y a la reflexión de la postura judicial en las responsabilidades jurídicas que derivan para el agente público por las "ejecuciones extrajudiciales", y si la posición tradicional de la jurisprudencia en Colombia del deudo patrimonial de la Fuerza Pública frente a las víctimas guarda coherencia con la conceptualización y teorización de la responsabilidad patrimonial a la luz del artículo 90 superior. Y es que se entiende la postura tradicional, pues el garantismo y el respeto por el derecho de la víctima deben irradiar la actuación del operador jurídico; sin embargo, se debe asumir una posición imparcial.

El régimen de responsabilidad patrimonial del Estado requiere la confirmación del principio de imputabilidad, según el cual la indemnización del daño antijurídico se atribuye al Estado cuando haya el soporte fáctico y la atribución jurídica.

La jurisprudencia nacional ha recabado en ello al sentar la tesis de que la base de la responsabilidad patrimonial del Estado la constituye la imputabilidad del daño. En efecto, con fundamento en la jurisprudencia del Consejo de Estado, la Corte Constitucional ha sostenido que la responsabilidad patrimonial del Estado y de las demás personas jurídicas públicas se deriva de la imputabilidad del perjuicio a una de ellas, lo cual impide extenderla a la conducta de los particulares o a las acciones

21 Mediante la Ley 16 de 1972 (publicada en el Diario Oficial N. ${ }^{\circ} 33.780$ del 5 de febrero de 1973), el Estado colombiano aprobó la Convención Americana sobre Derechos Humanos. 
u omisiones que tengan lugar por fuera del ámbito de la administración pública ${ }^{22}$. Si la imputación tiene relación con el servicio (por el cumplimiento de finalidades y funciones asignadas por la Constitución, la ley y el reglamento a la Fuerza Pública), el evento no guarda relación con la labor funcional que el constituyente asignó, sino que derivó de las condiciones y de los medios, sean instrumentales o temporales, y no podría concebirse como deber de la institución pública reparar la víctima, pues la actuación, si bien se produjo con la ocasión que el servicio permitió, no está ligada a la finalidad y a las potestades del Estado y que se desarrollan por su agente público. Cualquier acto desligado del desarrollo de la función pública asignada al servidor o agente de la Fuerza Militar o de Policía implicaría en ejercicio que desatiende las misiones constitucionales, como así lo imponen los artículos 95, 209, 217, 218 de la Carta Política, entre otros.

La ausencia de responsabilidad del Estado, sin embargo, no dejaría desprovista a la víctima de la reparación integral del perjuicio, y es que el deber resarcitorio muta de deudo o por lo menos radica en una sola persona: el agente público comprometido. Lo que sí se requiere es la existencia de mecanismos que aseguren, preventivamente, que el servidor de la Fuerza Pública asome con el suficiente respaldo patrimonial, si es el caso, ante la ocurrencia del suceso.

\section{EJECUCIONES EXTRAJUDICIALES O FALSOS POSITIVOS}

La proliferación de actuaciones irregulares de miembros de la Fuerza Pública que tuvo lugar durante la administración del gobierno de Álvaro Uribe Vélez ${ }^{23}$, con ocasión de la reglamentación de incentivos económicos a favor de los miembros de los cuerpos de defensa estatales para lograr muestras de resultados efectivos en el proceso de contrarrestar acciones de grupos armados al margen de la ley, ha traído impactos sociales y económicos para las arcas públicas, pues estos sucesos han derivado en reclamaciones patrimoniales que han resultado avaladas por las decisiones de la

22 Corte Constitucional de Colombia. SEnTEnCIA C-254 DE 2003. (M.P. Marco Gerardo Monroy Cabra; 16 de abril de 2003).

23 Político y abogado colombiano que fue elegido presidente de la república de Colombia en 2002 y fue reelegido en 2006, luego de una reforma constitucional que su gobierno promovió en el Congreso. 
jurisdicción contenciosa administrativa ${ }^{24}$. A pesar de que en estos eventos los servidores públicos no actúan movidos por el servicio, y por tanto no podría imputarse el daño a la entidad oficial, el Consejo de Estado ha reconocido la obligación resarcitoria de la entidad frente a las víctimas, contrariando tesis y posturas claras que han permitido diferenciar la falta personal de la falla de la administración y crear un espacio de discusión en el tema, que se hace imperioso para establecer límites al concepto de imputabilidad como componente de la responsabilidad patrimonial conforme al artículo 90 constitucional.

El anómalo evento de los vociferados "falsos positivos" o "ejecuciones sumarias"25 (es decir, los homicidios consumados por las fuerzas de seguridad del Estado contra civiles indefensos que luego son exhibidos ante las mismas autoridades y la colectividad como guerrilleros o insurgentes dados de baja para obtener privilegios económicos o institucionales) es tristemente ilustre para los colombianos. Si bien hay muestras de esos asuntos que se remontan a los años ochenta, las pruebas documentales indican que comenzaron a ocurrir con una frecuencia alarmante a partir del año 2004.

El Estado colombiano es depositario de instrumentos de derecho internacional público que regulan el Derecho Internacional Humanitario y el Derecho Internacional de Derechos Humanos ${ }^{26}$, y como tal, es forzoso respetarlo y aplicarlo. Esa imposición es predicable lógicamente para los miembros de las Fuerzas Militares, receptores nativos de las reglas y pautas del compendio normativo humanitario. En consecuencia, en desarrollo de la misión asignada en el artículo 217 de la Constitución Política, las Fuerzas Militares deben sujetarse irrestrictamente a la normativa humanitaria.

El Dr. Diego López Medina sostiene en su texto La armonización del derecho internacional de los derechos humanos con el derecho penal colombiano ${ }^{27}$.

24 Consejo de Estado, Sala de lo Contencioso Administrativo, Sección Tercera, entre otras. Sentencia del 14 de diciembre de 1993. Consejero ponente: Daniel Suárez Hernández. Expediente 8493. Actor: Segundo Jorge Pantoja Moreno; Consejo de Estado, Sala de lo Contencioso Administrativo, Sección Tercera, entre otras. Sentencia del 11 de noviembre de 2009. Consejero ponente: Enrique Gil Botero. Radicación: 05001-23-25-0001998-02246-01(35529).

25 Los miembros de las fuerzas armadas a menudo se refieren a los falsos positivos como "legalizaciones", es decir, homicidios que se han hecho aparecer como si fueran bajas en combate.

26 Hay varios instrumentos sobre derechos humanos, y entre los más relevantes para este continente están: la Declaración Universal de Derechos Humanos, la Declaración Americana de Derechos y Deberes del Hombre, el Pacto Internacional de Derechos Civiles y Políticos, y la Convención Americana sobre Derechos Humanos.

27 Diego Eduardo López Medina y Astrid Liliana Sánchez Mejía. LA ARMONIZACIÓN DEL DERECHO INTERNACIONAL DE LOS DERECHOS HUMANOS CON EL DERECHO PENAL COLOMBIANO. Editorial Universidad Javeriana. (2008). 
La articulación entre el derecho nacional de los derechos fundamentales (DNDF) y el derecho internacional de los derechos humanos (DIDH) ha sido clave en el lento proceso de consolidación de los derechos fundamentales y los derechos humanos en Colombia, en particular en el escenario de la justicia penal. La creciente armonización de estos dos cuerpos normativos ha tenido un impacto particular en el proceso penal interno, hasta el punto de que la transformación del sistema de procedimiento penal adelantada a través de la reforma constitucional del 2002 y el Código de Procedimiento Penal de 2004 se fundamentó en la necesidad de satisfacer los estándares internacionales de derechos humanos.

Lo anterior indica el acentuado y creciente fenómeno de la globalización del derecho, es decir, el acoplamiento de los regímenes internos a las legislaciones supranacionales, que son punto de partida y esquemas normativos complementarios.

En Colombia, son aplicables las reglas contenidas en los Convenios de Ginebra de $1949^{28}$, incorporados al ordenamiento jurídico en virtud del bloque de constitucionalidad ${ }^{29}$, aprobados por medio de la Ley 5 de 196030, el Protocolo II de 1977 Adicional a estos Convenios, relativo a la protección de las víctimas de los conflictos armados sin carácter internacional, aprobado mediante la Ley 171 de 1994.

La relevancia de estos estatutos jurídicos supraconstitucionales ha sido de tal magnitud que algunas de las transgresiones al Derecho Internacional Humanitario están normadas como ilicitudes en el Código Penal colombiano, Ley 599 de 2000, bajo el capítulo "Delitos contra personas y bienes protegidos por el Derecho Internacional Humanitario". Por su parte, en la Ley 836 de 2003, por remisión a la Ley 734 de 2002, se refiere como falta gravísima a incurrir en graves violaciones al Derecho Internacional Humanitario.

28 Casi todos los Estados son signatarios de los cuatro Convenios de Ginebra del 12 de agosto de 1949, que son tratados de derecho internacional.

29 En virtud de la figura, los jueces están sujetos a tener presente los instrumentos internacionales que se incorporan en nuestro compendio normativo, tal como puede interpretarse del contenido del artículo 93 constitucional. De allí que la jurisprudencia de los intérpretes autorizados de los instrumentos que hacen parte del bloque de constitucionalidad resultan efectivos al momento de dilucidar el alcance de los derechos humanos y del propio Derecho Internacional Humanitario, y las maneras de su reparación.

30 Promulgados a través del Decreto 1016 de 1990. 
La imposición normativa del artículo $217^{31}$ constitucional erige a las Fuerzas Militares como el organismo estatal cuya existencia está determinada por la defensa de la soberanía, la independencia, la integridad del territorio nacional y del orden constitucional. Por ello, las muertes o bajas de quien atente contra estos intereses, producidas en combate y como consecuencia del uso proporcional de la fuerza, son legítimas, pero cuando aquellas muertes en combate son el resultado de la inaplicación de los principios de "necesidad y proporcionalidad", son consideradas violaciones al derecho a la vida, que constituyen crímenes de guerra, competencia de la Corte Penal Internacional, y surgen las denominadas ejecuciones extrajudiciales, sumarias o arbitrarias, en el marco del Derecho Internacional de los Derechos Humanos. Para los efectos de la investigación, se recurrirá a algunas definiciones propuestas por la literatura especializada y por los órganos jurisdiccionales competentes para estos asuntos específicos, como la Corte Penal Internacional, y la Comisión y la Corte Interamericana de Derechos Humanos, que permiten discernir con precisión sobre las consecuencias del asunto.

\section{Definiciones doctrinarias}

Es indispensable partir de las múltiples definiciones que se hallan en diversos escritos nacionales y extranjeros respecto a lo considerado como "ejecuciones extrajudiciales" o falsos positivos.

El Consejo de Estado ha insistido en sostener que los "falsos positivos" consisten en "homicidios perpetrados por las fuerzas de seguridad del Estado contra civiles indefensos que luego son presentados ante las autoridades y ante los medios de comunicación como guerrilleros o delincuentes muertos en combate para obtener privilegios económicos o institucionales"32. Coincide con las apreciaciones de órganos internacionales que igualmente los ha entendido como "homicidios perpetrados por agentes del Estado colocando a la víctima en situación de indefensión o inferioridad" o como "casos de violaciones a los derechos humanos que consisten en el homicidio

31 “La Nación tendrá para su defensa unas Fuerzas Militares permanentes constituidas por el Ejército, la Armada y la Fuerza Aérea. Las Fuerzas Militares tendrán como finalidad primordial la defensa de la soberanía, la independencia, la integridad del territorio nacional y del orden constitucional. La Ley determinará el sistema de reemplazos en las Fuerzas Militares, así como los ascensos, derechos y obligaciones de sus miembros y el régimen especial de carrera, prestacional y disciplinario, que les es propio". (Cursiva fuera de texto).

32 Consejo de Estado, Sala de lo Contencioso Administrativo, Sección Tercera, Subsección B. Sentencia del 29 de marzo de 2012, Expediente 21380. Radicación 20001-23-31000-1999-00655-01. Consejero ponente: Danilo Rojas Betancourth. 
de manera deliberada de una persona por parte de un servidor público que se apoya en la potestad de un Estado para justificar el crimen"33. Puede ser considerada como todo acto arbitrario cumplido por un agente del Estado en ejercicio de sus funciones o hasta realizada por terceros con su instigación, aprobación o beneplácito, que tenga como finalidad privar de la vida a una persona o a varias personas. Incluye las muertes intencionalmente producidas, es decir, las nominadas ejecuciones arbitrarias, así como aquellas producidas por negligencia o uso desmedido o colosal de la fuerza:

Una ejecución extrajudicial es el hecho de violencia en el cual servidores públicos (o particulares que actúan teniendo a empleados oficiales como coautores, determinadores o cómplices) dan muerte injusta y premeditada a una persona para castigarla por lo que piensa, por lo que opina, por lo que hace, o en ocasiones simplemente por lo que es. Las ejecuciones extrajudiciales deben distinguirse de los atentados contra la vida, cometidos por individuos particulares que actúan sin tener nexo alguno con el Estado.34

Es decir, se caracteriza por constituir el resultado de una política o estrategia estatal, o que por lo menos el evento deriva de las circunstancias en las que la administración pública pone al agente, o los medios y circunstancias favorecen el crimen.

La Comisión de Derechos Humanos de las Naciones Unidas, con la finalidad de estudiar estos temas, designó un relator especial sobre ejecuciones extrajudiciales, quien ha entendido estas prácticas como:

Privación arbitraria de la vida como resultado de una sentencia impuesta mediante un procedimiento sumario en el que no se han respetado las garantías mínimas estipuladas en el Pacto Internacional de Derechos Civiles y Políticos (PIDCP) y en las salvaguardias para garantizar la protección de los derechos de los condenados a la pena de muerte.

Privación arbitraria de la vida como resultado de homicidios perpetrados por orden de un gobierno o con complicidad o tolerancia o aquiescencia sin un proceso judicial o legal. Privación arbitraria de la vida de civiles por

33 Organización de las Naciones Unidas. Disponible en: www.un.org/es.

34 Mario Madrid-Malo Garizábal. Ejecuciones extrajudiciales. EL CATOLICıSMO N.` 95.2 de junio de 2005. 
La imputabilidad en la responsabilidad patrimonial del Estado en las denominadas ejecuciones extrajudiciales y la derivada para los agentes públicos

miembros de las fuerzas armadas o de seguridad en violación de las leyes que rigen el estado de guerra o del conflicto armado. ${ }^{35}$

Escritores internacionales como el antropólogo Gilberto Lópezy Guillermo Rivas, en su artículo titulado "Los crímenes de Estado de Álvaro Uribe Vélez", exponen que los "falsos positivos son los civiles asesinados y posteriormente presentados como 'bajas de la guerrilla en combate', cuyos cadáveres son uniformados y armados por los victimarios para cobrar las recompensas, estímulos y ascensos que Uribe ofrece. Los familiares de las víctimas se oponen a este término y se refieren a 'ejecuciones extrajudiciales como crímenes de Estado'"'36. Se mantiene el elemento característico, la motivación o incitación del Estado a la comisión de la ilicitud:

Los "falsos positivos" no son solamente, como se ha dicho, montajes de atentados (frustrados o llevados a efecto) o mentiras para responsabilizar a los grupos insurgentes de masacres cometidas por otros actores. De hecho, la manera más frecuente en que este término se usa es con los centenares de casos de campesinos desprevenidos que han sido asesinados por el ejército y luego presentados como guerrilleros dados de baja en combate, a fin de cobrar de esta manera beneficios y, de paso, dar los "resultados" que tanto exigen sus superiores. ${ }^{37}$

Lastimosamente, en estos hechos son las personas más indefensas, y no desde el punto de vista bélico, sino desde la óptica del desamparo estatal y social, o las personas de escasos medios económicos, con un nivel de educación por debajo del promedio, los objetivos preferidos de la Fuerza Pública, cuyos miembros aprovechan obviamente la exigua credibilidad y escaso eco que pueden tener las voces de protesta de sus familiares.

La dinámica fáctica de estos casos está bien documentada, por lo que solo será necesario aquí delinear las pautas generales comunes a todos los departamentos del país. En algunos casos, un "reclutador" pagado

35 Organización de las Naciones Unidas. FOLLETO INFORMATIVO N. ${ }^{\circ}$ 11. EJECUCIONES SUMARIAS O ARBITRARIAS. 1989. Disponible en: www.un.org/es.

36 Gilberto López y Guillermo Rivas Pacheco. Los crímenes de Estado de Álvaro Uribe Vélez. BLog REBELIón. 20 de marzo de 2009. Disponible en: https://rebelion.org/los-crimenes-de-estado-de-alvaro-uribe-velez/

37 José Antonio Gutiérrez. Los falsos positivos: los horrores de una guerra mediática. ANARKISMO. 11 de octubre de 2008. Disponible en: http://www.anarkismo.net/article/10199 
(un civil, un miembro desmovilizado de un grupo armado o un exmilitar) atrae a las víctimas civiles a un lugar apartado engañándolas con un señuelo, por lo general la promesa de un trabajo. Una vez allí, las víctimas son asesinadas por miembros de las fuerzas militares, a menudo pocos días u horas después de haber sido vistos por los familiares por última vez. En otros casos, las fuerzas de seguridad sacan a las víctimas de sus hogares o las recogen en el curso de una patrulla o de un control de carretera. Las víctimas también pueden ser escogidas por "informantes", que las señalan como guerrilleros o delincuentes a los militares, a menudo a cambio de una recompensa monetaria. Una vez que estas víctimas son asesinadas, las fuerzas militares organizan un montaje de la escena, con distintos grados de habilidad, para que parezca un homicidio legítimo ocurrido en combate.

El montaje puede entrañar, entre otras cosas, poner armas en manos de las víctimas; disparar armas de las manos de las víctimas; cambiar su ropa por indumentaria de combate $u$ otras prendas asociadas con los guerrilleros; o calzarlas con botas de combate. Las víctimas son presentadas por los militares y anunciadas a la prensa como guerrilleros o delincuentes abatidos en combate. A menudo se entierra a las víctimas sin haberlas identificado (bajo nombre desconocido), y en algunos casos en fosas comunes. Entre tanto, los familiares de las víctimas buscan con desesperación a sus seres queridos, a veces durante muchos meses. Cuando los miembros de la familia descubren lo sucedido y toman medidas para tratar de que se haga justicia, por ejemplo denunciando el caso a las autoridades o señalándolo a la prensa, suelen ser objeto de intimidaciones y amenazas y algunos de ellos han sido asesinados.38

El agente público que comete un hecho ilícito de los denominados falsos positivos conoce las circunstancias que acompañan el evento dañino, y aún más las repercusiones del suceso, es decir que es imputable por tener el "mínimo de capacidad para comprender las connotaciones antijurídicas de su comportamiento y para determinarse conforme a ese entendimiento. Esa capacidad supone, entonces, conceptos biológicos (mayoría de edad, oír y/o hablar), siquiátricos (sanidad mental),

38 Informe de la Misión a Colombia presentado a la Asamblea General de las Naciones Unidas por el Relator Especial sobre las ejecuciones extrajudiciales, sumarias o arbitrarias, Philip Alston. Marzo 31 de 2010, párr. 10 y 11. 
sicológicos (madurez síquica y voluntariedad) y antropológicos (entendimiento de los patrones socioculturales que imperan en un medio extraño)"39.

La mayoría de las concepciones de "falsos positivos" o "ejecuciones extrajudiciales o ejecuciones sumarias" coincide en un ingrediente sustancial: los elementos motivadores del atroz evento están en las resueltas políticas estatales. De ahí que con mayor rigor algunas de las citas que se transcribieron in extenso arremeten en el estudio temporo-espacial específico del mandato del Uribe Vélez, periodo en el que se produjeron, como lo reseñaremos más adelante, directivas ministeriales que exigían un alto punto de laboriosidad de las Fuerzas Militares y muestras efectivas de sus misiones. No obstante, y sin que la posición de esta investigación pueda tildarse de descabellada o como una concepción permisiva de los actos irregulares del Estado, respetando a quienes consideran sin dubitación la obligatoriedad de reparación a cargo de la administración pública, son varias las razones (que se explicarán al final de este capítulo) que permiten absolver a la institución gubernamental de los cargos de responsabilidad que se han levantado.

Una política, una directiva, una estrategia pública está orientada en esencia a motivar o a alentar el desarrollo eficiente y eficaz de una tarea; es decir, comprende el conjunto de actividades de las instituciones de gobierno que van dirigidas a tener una influencia determinada sobre el conglomerado, que se llevan a cabo de manera temporal, producto de lo que no se había podido realizar, pero con apego a los procedimientos que la ley y la Constitución avalan.

La exigencia en la obtención de resultados se consideraría, por quienes están envueltos solo en las lides jurídicas, un método acertado de una buena gerencia. Responsabilizar al Estado por los medios utilizados por sus agentes para demostrar eficiencia y eficacia es hacerlo responsable de la voluntad de su representante. No puede pensarse que para el ente público, como lo sostuvo Nicolás Maquiavelo, el fin justifique los medios, esto es que el poder estatal ha de estar superpuesto a la ética y la moral para conseguir sus fines o llevar a cabo sus propósitos. La política o estrategia gubernamental, como el tema de las directivas ministeriales, o si se quiere el sistema de premios establecidos por el legislador, tratándose de las Fuerzas Militares y Policiales, es el resultado no solo del establecimiento de la agenda política, sino también de la identificación de un grave problema de insurgencia, que obligó al establecimiento de objetivos. Si la política fue correcta, es un proceso que se evalúa con posterioridad, después de determinar los valores que están detrás de sus objetivos. El problema no puede radicarse en la política del Estado, sino en el mecanismo al

39 Leonel Calderón Cadavid. LA INIMPUTABILIDAD EN EL DERECHO PENAL Y EN EL PROCEDIMIENTO. Editorial Temis. (1996). 
que su agente acude para cumplir sin estupor, sin sensibilidad social y humana, sin hesitación, sin valor y vergüenza alguna, lo cual pone al margen del hecho el objetivo institucional. Así lo trataremos en su correspondiente acápite.

\section{Reporte de autoridades supranacionales sobre el tema}

El alcance de estos eventos ha sido de tal magnitud que organismos internacionales han resuelto ocuparse sin mayor reserva, dándolos a conocer a la comunidad internacional. Por ejemplo, como ya se citó, en marzo de 2010 el Relator Especial sobre las ejecuciones extrajudiciales, sumarias o arbitrarias, señor Philip Alston, informó al Consejo de Derechos Humanos de la ONU, en su decimocuarto periodo de sesiones, sobre la misión adelantada al respecto en Colombia:

Las fuerzas de seguridad han perpetrado un elevado número de asesinatos premeditados de civiles y han presentado fraudulentamente a esos civiles como "bajas en combate". Aunque al parecer estos Ilamados falsos positivos no respondían a una política de Estado, tampoco fueron hechos aislados. Esos homicidios fueron cometidos por un gran número de unidades militares y en todo el país. Se produjeron porque las unidades militares se sintieron presionadas para demostrar que su lucha contra las guerrillas tenía resultados positivos a través del "número de bajas". Hubo además algunos alicientes: un sistema oficioso de incentivos ofrecidos a los soldados para que produjeran bajas y un sistema oficial de incentivos ofrecidos a los civiles para que proporcionaran información que condujera a la captura o muerte de guerrilleros. Este último sistema careció de supervisión y transparencia. En general, hubo una falta fundamental de rendición de cuentas y problemas en todas las etapas de los procesos disciplinarios y de investigación. ${ }^{40}$

Lo más alarmante del asunto es la forma y la dinámica usada por las fuerzas del orden, que el mismo informe señala:

En algunos casos, un "reclutador" pagado (un civil, un miembro desmovilizado de un grupo armado o un exmilitar) atrae a las víctimas civiles a un lugar apartado engañándolas con un señuelo, por lo general la promesa

40 Disponible en: http://www.hcr.or.co/documentosinformes/altocomisionado/informe 2010/esp.doc. 
de un trabajo. Una vez allí, las víctimas son asesinadas por miembros de las fuerzas militares, a menudo pocos días u horas después de haber sido vistos por los familiares por última vez. En otros casos, las fuerzas de seguridad sacan a las víctimas de sus hogares o las recogen en el curso de una patrulla o de un control de carretera. Las víctimas también pueden ser escogidas por "informantes", que las señalan como guerrilleros o delincuentes a los militares, a menudo a cambio de una recompensa monetaria. Una vez que estas víctimas son asesinadas, las fuerzas militares organizan un montaje de la escena, con distintos grados de habilidad, para que parezca un homicidio legítimo ocurrido en combate. El montaje puede entrañar, entre otras cosas, poner armas en manos de las víctimas; disparar armas de las manos de las víctimas; cambiar su ropa por indumentaria de combate $u$ otras prendas asociadas con los guerriIleros; o calzarlas con botas de combate [que exterioriza la artimaña y el desenvolvimiento de actos meramente personales sin conexión con la finalidad estatal].

El informe destaca que "la falta de atribución de la responsabilidad penal ha sido un factor clave para que sigan produciéndose casos de falsos positivos", sumado a que en algunos lugares:

[...] parece existir un intento consciente por parte de los jueces militares de frustrar los esfuerzos del sistema de justicia civil. Esto además retrasa enormemente, a veces meses o años, la investigación y el conocimiento por los tribunales de las denuncias de ejecuciones extrajudiciales, en tanto que los presuntos autores están en libertad y los testimonios y las pruebas pueden perder su eficacia. Los jueces militares que colaboran con el sistema de justicia civil pueden ser objeto de acoso, amenazas o traslado a otras jurisdicciones.

La impunidad y la colusión han sido un factor determinante en el debido enjuiciamiento de estos atroces acontecimientos, sin dejar de lado la cuestionada eficacia de la jurisdicción penal militar. 


\section{De las políticas estatales}

La promoción de incentivos por los estamentos gubernamentales ha constituido, según las citas de la doctrina referida, una de las causas de estos aberrantes y absurdos hechos. Aunque no puede ser ajeno lo que en el mismo Estatuto Disciplinario de las Fuerzas Militares, Ley 836 de 2003, se encuentra como parte de los estímulos en aras de congraciarse con la institución ${ }^{41}$. Es necesario un repaso de algunas de las directrices o directivas estatales que han generado, con mayor énfasis durante esta última década, la proliferación de estos eventos.

En 1998, en la Directiva 018 MDN-SEG-252 se estableció un sistema de pago de recompensas por la captura de cabecillas de grupos al margen de la ley. Cuando Álvaro Uribe Vélez tomó posesión como primer mandatario de la república en el año 2002, planteó la lucha contrainsurgente como eje primordial de su administración, por ello se adoptaron medidas en el marco de la llamada política de seguridad democrática. Esas medidas otorgaban una serie de facultades a las Fuerzas Militares ${ }^{42}$. En el año 2003, el objetivo de la Directiva 09 de $2005^{43}$ fue fortalecer la política de promoción y protección de los derechos humanos de trabajadores, sindicalistas y defensores de derechos humanos, que fijó al Comando General de las Fuerzas Militares y a la Dirección General de la Policía Nacional la obligación de informar al Ministerio de Defensa los resultados de las acciones que se adelantaban para proteger los derechos de líderes sindicales y defensores de derechos humanos.

Obviamente, el afán de resultados hizo proclive a la Fuerza Pública a disfrazar situaciones para el cumplimiento de los objetivos trazados por el despacho ministerial, desatando actos criminales propios del delincuente nato, ya que el comportamiento criminal no puede atribuirse por completo y en absoluto a un condicionamiento exterior, sino a la disposición natural de estos agentes públicos.

La Directiva 09 de 2005, en el mismo sentido, trazó como objetivo la necesidad de "crear una política de protección y prevención en situaciones de desplazamiento forzado por la violencia", en la que las Fuerzas Militares y la Policía Nacional están en la obligación de adelantar operaciones militares y policiales para desmantelar las organizaciones que generan el desplazamiento forzado, y a su vez se les atribuye

41 El capítulo IV de dicha normatividad desarrolla el tema de los estímulos.

42 El estado de excepción se declaró mediante el Decreto 1837 del 11 de agosto de 2002. Posteriormente, mediante el Decreto 2002 de 2002 se crearon las zonas de rehabilitación y consolidación con poderes extraordinarios a las Fuerzas Militares para realizar operaciones militares y restringir o limitar los derechos a la libertad, al debido proceso y a la circulación de la población civil, dado que se las vinculaba o asociaba con grupos guerrilleros.

43 Expedida por Martha Lucía Ramírez de Rincón, en su condición de titular del Ministerio de Defensa durante el primer periodo presidencial de Álvaro Uribe Vélez. 
el deber a los comandantes de dichas dependencias de pasar un reporte trimestral de sus acciones al Ministerio de Defensa, a la Red de Solidaridad Social y a la Vicepresidencia de la República.

Con idénticas exigencias, se expidieron la Directiva 01 de $2007^{44}$ sobre el retorno de desplazados ${ }^{45}$ y la Directiva 16 de 2006 con la meta de fortalecer la política de reconocimiento, prevención y protección de los derechos humanos de las comunidades de los pueblos indígenas por parte de la Fuerza Pública, entre otras normatividades. Esto ha creado el ambiente propicio para que, en el afán de alcanzar las metas estatales, se desarrollen actividades militares y policiales con el atropello a los derechos de los ciudadanos, mostrado como parte de los resultados exigidos.

Lo relevante de las estrategias gubernamentales surgió el 17 de noviembre de $2005^{46}$ con la número 20 , que establece y desarrolla criterios para el pago de recompensas por la captura o abatimiento en combate de cabecillas de las organizaciones armadas al margen de la ley, material de guerra, intendencia o comunicaciones e información sobre actividades relacionadas con el narcotráfico y pago de información que sirva de fundamento para las labores de inteligencia y el posterior planeamiento de operaciones. Señaló la directriz como objetivos específıcos, entre otros: i) definir pago por información y pago por recompensas ${ }^{47}$; ii) fijar criterios de valoración para cancelar recompensas por los principales cabecillas de las organizaciones al margen de la ley y los cabecillas de narcotráfico, de tal forma que sirva para reducir los incentivos del terrorismo y otros delitos como el secuestro; iii) establecer montos claros y predeterminados para cancelar recompensas por material de guerra ${ }^{48}$, intendencia 0 comunicaciones o actividades relacionadas con el narcotráfico.

El 20 de noviembre de 2007, con la Directiva Permanente 300-28, se propuso como finalidad "privilegiar como medición de los resultados operacionales las desmovilizaciones colectivas e individuales sobre las capturas, y de estas a su vez sobre las muertes en combate, y dar mayor valoración a las muertes en combate cuando se

44 Cuyo objetivo es: "Establecer el protocolo para la valoración de los aspectos de seguridad por parte de la Fuerza Pública en los procesos de retorno o reubicación de la población en situación de desplazamiento forzado por la violencia y complementar la política del Ministerio de Defensa en materia de desplazamiento".

45 Lizandro Cabrera Suárez. El desplazamiento en Colombia y sus diversas miradas. DIXI 25. Abril de 2017. Disponible en: https://doi.org/10.16925/di.v19i25.1818

46 Firmado por el ministro Camilo Ospina Bernal.

47 Según el mismo documento, consiste en la retribución en dinero o en especie, previamente establecida por el Gobierno nacional, a una persona indeterminada por informaciones oportunas y veraces proporcionadas a la Fuerza Pública.

48 Lizandro Cabrera Suárez. La paz: mucho más que el final de la guerra. DIXI 23. Abril de 2016. Disponible en: https://doi.org/10.16925/di.v18i23.1289 
trate de cabecillas, lo cual contribuirá de manera eficaz a los objetivos de la Política de Seguridad Democrática". El Comando General de las Fuerzas Militares dispuso a partir de dicha fecha lo siguiente:

[...] privilegiar como medición de los resultados operacionales las desmovilizaciones colectivas e individuales sobre las capturas y de estas sobre las muertes en combate, dar mayor valoración a las muertes en combate cuando se trate de cabecillas, contribuyendo de manera eficaz a los objetivos de la Política de Seguridad Democrática y realizar el análisis de los resultados operacionales alcanzados y sus efectos en los campos del poder político, económico, social y militar, mediante el balance operacional que permita demostrar la efectividad y contundencia de la capacidad operacional de las Fuerzas Militares en la defensa, protección y garantía de los derechos humanos y en la aplicación y respeto de la normativa humanitaria.

Se sumó a estas propuestas el Decreto 1400 de mayo de 2006, que creó la bonificación por operaciones de importancia nacional para los miembros de la Fuerza Pública y funcionarios del Departamento Administrativo de Seguridad (DAS) que participen en una operación de importancia nacional ${ }^{49}$. Esta además podía ser otorgada a una misma persona tantas veces como se haga acreedora de ella.

La bonificación estuvo fijada hasta por un valor equivalente a doce asignaciones básicas mensuales que perciba el miembro de la Fuerza Pública o el funcionario del DAS. Además, el ministro de Defensa Nacional podía proponer a consideración del presidente de la república las operaciones realizadas por miembros de la Fuerza Pública y funcionarios del DAS, y de conformidad con los parámetros establecidos en el mismo decreto determinaría si eran consideradas como de importancia nacional. No obstante, la vigencia de esta norma se prolongó hasta el 14 de mayo de 2007 cuando fue derogada por el Decreto 1664 de 2007.

El recorrido propuesto permite concluir que las políticas públicas fueron y son delineadas y producidas sin estimar de manera suficiente su impacto en la promoción y defensa de los derechos humanos, pues el tipo de instrumentos legales se convirtieron en un trofeo que mercenariza el conflicto armado y falsea las consecuencias firmes y efectivas de la política de seguridad democrática. A partir de estas

49 Según la misma regulación normativa, las operaciones de importancia nacional las constituían aquellas operaciones en las cuales se lograra la captura de los cabecillas de los niveles I y II que se encuentran determinados en la directiva expedida por el Ministro de Defensa Nacional (artículo 2). 
estructuras legales, las ejecuciones extrajudiciales se convirtieron, lastimosamente, en un potencial y creciente negocio del crimen, como lo testifican las estadísticas de la Unidad de Derechos Humanos ${ }^{50}$ de la Fiscalía General de la Nación ${ }^{51}$.

El Observatorio de Paz Integral en el Magdalena Medio, en un documento titulado Desaparición forzada y ejecuciones extrajudiciales presentadas como resultados positivos en combate. Degradación del conflicto armado colombiano. Una mirada desde el Magdalena Medio Colombiano ${ }^{52}$, al respecto citó:

\begin{abstract}
Estos presuntos hechos son premiados o bonificados con ascensos en la carrera militar, bajo la siguiente lógica: mostrar bajas del actor enemigo es tomado como muestra del progreso en la guerra contrainsurgente. En la realidad no existen las bajas en el campo de operaciones militares, sino la ejecución extrajudicial de personas civiles, o de combatientes en estado de indefensión. Esta práctica es conocida como "body count" por el Departamento de Estado de Estados Unidos. En la Región del
\end{abstract}

50 Lizandro Cabrera Suárez. El control de convencionalidad y la protección de los derechos humanos en Colombia. DIXI 19. Junio de 2014. Pág. 53-70. Disponible en: https:// doi.org/10.16925/di.v16i19.732

51 "Según las estadísticas de la Unidad de Derechos Humanos de la Fiscalía General de la Nación, tras la expedición de la Directiva Ministerial 029 de 2005, se pasó de 73 denuncias por casos de ejecuciones extrajudiciales contra la Fuerza Pública en 2005, a 122 en 2006 y 245 en 2007. Además, a partir de 2003, la Oficina del Alto Comisionado de Naciones Unidas comenzó a notar en sus informes un aumento de los casos de ejecuciones extrajudiciales cometidos por la Fuerza Pública. A partir de 2005, la Oficina del Alto Comisionado empieza a denunciar los casos de falsos positivos: "Llamaron la atención los casos de ejecuciones extrajudiciales de personas cuyos cuerpos fueron posteriormente presentados ante los medios como guerrilleros o paramilitares abatidos en combate". En 2006, la Oficina advirtió que había observado "un incremento en las denuncias sobre acciones atribuidas a miembros de la Fuerza Pública, y particularmente del Ejército. Esto se manifestó especialmente en el departamento de Antioquia, así como en Chocó, Norte de Santander, y en la región de la Sierra Nevada de Santa Marta. La mayoría de estas ejecuciones ha sido presentada por las autoridades como muertes de guerrilleros en combate, con alteraciones de la escena del crimen. Muchas fueron investigadas indebidamente por la justicia penal militar. Se registraron casos en que los propios mandos habrían apoyado la acción de vestir a las víctimas con atuendos de guerrilleros para ocultar los hechos y simular una acción en combate [...] La práctica de estas conductas, su negación por ciertas autoridades y la ausencia de sanciones a sus autores plantean la eventual responsabilidad de los superiores jerárquicos". Ver: Movimiento Nacional de Víctimas de Crímenes de Estado (Movice). La guerra se mide en litros de sangre. FALSOS POSITIVOS, CRíMENES DE LESA HUMANIDAD: MÁS ALTOS RESPONSABLES EN LA IMPUNIDAD. Federación Internacional de Derechos Humanos. Disponible en: https://www.fidh.org/IMG/pdf/colombie589e.

52 Observatorio de Paz Integral (OPI). DESAPARICIÓN FORZADA Y EJECUCIONES EXTRAJUDICIALES PRESENTADAS COMO RESULTADOS POSITIVOS EN COMBATE. DEGRADACIÓN DEL CONFLICTO ARMADO COLOMBIANO. UNA MIRADA DESDE EL MAGDALENA MEDIO COLOMBIANO. OPI. (2013). 
Magdalena Medio, el Observatorio de Paz Integral (OPI), organizaciones sociales y defensoras de derechos humanos, han venido denunciando estos casos por más de 10 años, observando un importante incremento entre enero de 2006 a diciembre de 2008. En este periodo se desarrollaron operaciones militares en las que el Gobierno buscaba la "retoma del territorio" ocupado por los grupos paramilitares en proceso de desmovilización. Durante el mismo periodo, se registró el aumento de amenazas colectivas e individuales, desplazamientos, utilización de civiles como escudos humanos, pillaje, destrucción de bienes civiles, detenciones arbitrarias y las temibles ejecuciones extrajudiciales por cuenta del Ejército Nacional. Entre enero de 2006 y diciembre de 2008 el OPI ha registrado 165 casos de violación de DDHH por cuenta del Ejército Nacional y 47 ejecuciones a civiles presentados como combatientes.

Los interrogantes son: ¿qué responsabilidad se deriva para la administración pública por la actuación de su agente en este suceso?, ¿qué responsabilidad surge para el funcionario comprometido?, ¿son imputables a la institución estatal las consecuencias económicas de un hecho delictivo cometido durante el ejercicio de la función pública, pero que no encierra consumar la finalidad del Estado?

\section{RESPONSABILIDADES DERIVADAS PARA EL AGENTE DE LA FUERZA PÚBLICA EN LAS DENOMINADAS EJECUCIONES EXTRAJUDICIALES}

El artículo 6 de la Carta Superior indica que los servidores públicos son responsables por infringir la Constitución y las leyes, así como por omisión y extralimitación en el ejercicio de funciones, por eso se les permite hacer lo que tienen permitido y no hacer lo prohibido. Las autoridades públicas, incluyendo la Fuerza Pública, están instituidas para proteger a todas las personas en su vida, honra, bienes, creencias y demás derechos y libertades, sumado a la cláusula específica que contempla el artículo 217 constitucional, sin pasar por alto el postulado del artículo 95 "de respetar los derechos ajenos y no abusar de los propios". Esto encierra que cuando en ejercicio de función constitucional deba utilizarse la fuerza o su medio armamentístico, 
es porque el uso de estos mecanismos es la última de las herramientas a la que debe acudirse, por ser excepcional y extremo.

Si la operación militar o policial está destinada a socavar al disidente, o puede cegarse con la vida, estos injustos solo se explican cuando las exigencias del evento no permitan otra solución, ya que debe atemperarse al principio de racional proporcionalidad propio del derecho humanitario ${ }^{53}$ y de la Constitución Política (artículo 214). El cumplimiento y el ejercicio de la autoridad están sometidos a la Carta y a las leyes y al respeto de los derechos humanos, como supremo valor del Estado, porque en este modelo "el ciudadano no es para el Estado, sino que el Estado es para el hombre"54. Es sabido que quien mediante una conducta ilícita lesiona intereses particulares o los superiores de la colectividad, incurre no solo en responsabilidad penal, sino también en la civil o patrimonial, y tratándose de servidores públicos, son otras órbitas del derecho sancionador las que terminan inmersas.

Responsabilidad penal. Es aquella que se establece por los actos o conductas que instituyen infracciones estimadas como "actos delictuales" por la legislación penal. Nace en la medida "en que su conducta encuadre típicamente en algunas de las reprimidas por la norma penal de fondo. Es decir que, en este aspecto, la legislación penal actúa como límite externo y negativo para el agente [...]"55.

La Carta Constitucional concibe al Estado colombiano bajo un modelo de Estado social de derecho, fundado primordialmente en el respeto a la dignidad del hombre. Así, los conceptos del derecho penal, como otras ramas, deben instituirse en el marco de los contenidos que traza y delimita el nuevo modelo de Estado según los mandamientos superiores contenidos en sus artículos 1 y 2, con la ineludible necesidad de interpretarse a partir de los contenidos jurídicos de la Carta Superior y de los Tratados Internacionales de Derechos Humanos, como parte del bloque de constitucionalidad ${ }^{56}$ que conforman.

53 Por ejemplo, los Protocolos de Ginebra. Disponible en: http://www.icrc.org/spa/warand-law/treaties-customary-law/geneva-conventions/index.jsp.

54 Antonio Beristain. EL DELINCUENTE EN EL ESTADo SOCIAL DE DERECHO. Editorial Reus. (1971).

55 Fabián Omar Canda. Responsabilidad penal de los agentes de la administración pública. Ed. Fabián Omar Canda. RESPONSABILIDAD DEL ESTADO Y DEL FUNCIONARIO PÚBLICO. Editorial Ciencias de la Administración. (2001).

56 Corte Constitucional de Colombia. SENTENCIA C-370 DE 2006. (M.P. Manuel José Cepeda Espinosa, Jaime Córdoba Triviño, Rodrigo Escobar Gil, Marco Gerardo Monroy Cabra, Álvaro Tafur Galvis, Clara Inés Vargas Hernández; 18 de mayo de 2006): "Según el derecho constitucional, interpretado a la luz del bloque de constitucionalidad, los familiares de las personas que han sufrido violaciones directas a sus derechos humanos tienen derecho a presentarse ante las autoridades para que, demostrado el daño real, concreto y específico sufrido con ocasión de las actividades delictivas, se les permita solicitar la garantía de los derechos que les han sido vulnerados". 
La historia de Colombia muestra el desarrollo de un conflicto armado ya desde hace varias décadas, pues las circunstancias de hecho hacen tozudas las posiciones que niegan la condición bélica del país. Los conflictos armados tanto de carácter internacional como interno son regidos por el Derecho Internacional Humanitario (DIH), que inhibe una serie de comportamientos en el marco de un conflicto armado. Entre tales conductas, todas ellas punibles en el derecho penal, se encuentra el homicidio de no combatientes, es decir, de personas civiles que no participan en las hostilidades y de combatientes que se encuentran fuera del contexto hostil. Por su parte, "las exigencias y el mantenimiento del orden público serán siempre compatibles con el respeto a la persona humana"57.

El contexto que plantea la investigación tiene de relieve otras discusiones, ya bosquejadas por la doctrina, en cuanto a la trascendencia del acto ilícito del agente público en los falsos positivos, cuyo juzgamiento no solo acarrearía la sanción de la jurisdicción interna, sino también de la Corte Penal Internacional, de acogerse cierta tesis reinante entre expertos.

La Corte Penal Internacional en su Estatuto ${ }^{58}$ regula los crímenes de guerra en el artículo 8 que establece:

[...] c) En caso de conflicto armado que no sea de índole internacional, las violaciones graves del artículo 3 común a los cuatro Convenios de Ginebra de 12 de agosto de 1949, a saber, cualquiera de los siguientes actos cometidos contra personas que no participen directamente en las hostilidades [...]: i) los atentados contra la vida y la integridad corporal, especialmente el homicidio en todas sus formas, las mutilaciones, los tratos crueles y la tortura [...].

Nuestra legislación penal, obviamente, no es ajena a la tipificación de estas acciones y así lo hace en su artículo 135, que regula:

Homicidio en persona protegida. El que con ocasión y en desarrollo de conflicto armado, ocasione la muerte de persona protegida conforme

57 Jean Pictet. DESARROLLO Y PRINCIPIOS DEL DERECHO INTERNACIONAL HUMANITARIO. Instituto Henry Dunant. (1986).

58 Del cual hace parte Colombia desde el 1 de noviembre de 2002, en relación con los crímenes de genocidio y de lesa humanidad. Sin embargo, dado que Colombia firmó la reserva de siete años establecida en el artículo 124 del Estatuto, la vigencia para Colombia en relación con los crímenes de guerra comenzó formalmente el 1 de noviembre de 2009. 
a los Convenios Internacionales sobre Derecho Humanitario ratificados por Colombia, incurrirá en prisión de treinta (30) a cuarenta (40) años, multa de dos mil (2.000) a cinco mil (5.000) salarios mínimos legales mensuales vigentes, e inhabilitación para el ejercicio de derechos y funciones públicas de quince (15) a veinte (20) años.

El Estado colombiano, a pesar de que durante algún tiempo no tuvo la competencia de la Corte Penal Internacional, no eximía a las autoridades internas de iniciar las investigaciones y realizar las condenas por la acción considerada como crimen de lesa humanidad.

Las ilicitudes en los casos de falsos positivos o ejecuciones extrajudiciales inicialmente no ofrecen mayor complejidad para la legislación penal interna, pero la inquietud surgiría en entenderlos o no como una categoría de crímenes de guerra, o de lesa humanidad, pues así podrían calificarse las falsas bajas de civiles en combate, bien como homicidio agravado o como homicidio en persona protegida, esto es, como violación del DIH o crimen de guerra.

El crimen de lesa humanidad es un acto atroz, bárbaro y sin ningún comportamiento moral, tanto así que cualquier ser humano se indigna ante el evento, por la amoralidad y atrocidad que brota en su ejecución. Sin duda alguna, el sujeto pasivo lo constituye toda una colectividad, pues a pesar del daño particular, conmociona a toda la sociedad, afectada en su dignidad y conciencia. Si bien es cierto que la Corte Penal Internacional no tiene competencia sobre transgresiones a los derechos humanos como tales, los crímenes de lesa humanidad son, en efecto, graves violaciones de algunos derechos humanos cometidas en un escenario específico. Por tanto, las decisiones de este tribunal, con asiduidad, afrontan temas muy relevantes para la interpretación del derecho internacional de los derechos humanos. La discusión no puede echar de menos y tener en cuenta que para quienes debe ser considerado como homicidio agravado, apunta a que el suceso no tiene relación alguna con pugnas armadas como tal; sin embargo, como sustento de quienes explican que se trata de crímenes de guerra es precisamente porque los perpretadores se han valido del conflicto armado para el atropello contra civiles ajenos a la crisis. "Aunque los delitos de lesa humanidad por su parte no presuponen un estado de guerra y pueden ser sometidos en cualquier tiempo, pero lo que los caracteriza es sobre todo el poder de ofensa a la conciencia general"59.

59 Jesús Orlando Gómez López. LA OBEDIENCIA JERÁRaUICA Y LA INVIOLABILIDAD DE LOS DERECHOS HUMANOS. Ediciones Doctrina y Ley. (1998). Pág. 240. 
Los crímenes de lesa humanidad se diferencian de otras infracciones principalmente porque reúnen cuatro características: (i) son actos generalizados, que pretenden soslayar que se trata de ilícitos cometidos contra una gran cantidad de víctimas, ya sea por la cantidad de crímenes o por un crimen con muchas víctimas; (ii) son sistemáticos, pues su comisión se realiza con arreglo a un plan o política preconcebida que permite la realización repetida o continuada de dichos actos inhumanos; (iii) son perpetrados por las autoridades de un Estado o por particulares que actúan por instigación de dichas autoridades o con su tolerancia, ayuda o complicidad; y (iv) están dirigidos contra la población civil por motivos sociales, políticos, económicos, raciales, religiosos o culturales.

Es indefectible que el sujeto activo del crimen sea un agente estatal o particular que trabaja para el Estado o que actúa con su apoyo, beneplácito o tolerancia. Resulta absolutamente relevante la estimulación del crimen, pues este elemento permite comprender el sentido mismo del crimen de lesa humanidad al enmarcarlo dentro de un contexto social, político, económico y cultural preciso. Estos componentes los distinguen de otros crímenes como las violaciones a los derechos humanos y los abusos de autoridad, estos últimos con algunas de las particularidades de los crímenes de lesa humanidad, pero no las reúnen todas.

En gran medida, los falsos positivos o ejecuciones extrajudiciales, arbitrarias o sumarias cometidas en Colombia durante la última década (principalmente) reúnen caracteres propios de estos crímenes de lesa humanidad. Y es que basados en la jurisprudencia internacional en la materia, se encuentran particularidades que erigen la situación del país como el escenario propio de este tipo de crímenes.

El ataque dirigido contra una población civil. Se refiere a una operación lanzada contra la población civil, sin que sea necesario que se trate de un ataque militar ${ }^{60}$; la población civil debe ser el objetivo principal del ataque y no una simple víctima incidental ${ }^{61}$. "La población civil en Colombia ha sido indudablemente el objetivo de ataques en el marco del conflicto armado interno". En sus declaraciones luego de su visita a Colombia en 2009, el Relator Especial de Naciones Unidas sobre Ejecuciones Extrajudiciales destacó que las ejecuciones cometidas por las fuerzas de seguridad, paramilitares y otros agentes armados no estatales "repercuten de manera despro-

60 Corte Penal Internacional. Elementos de los crímenes, artículo 7, párr. 3. Disponible en: http://www.icrc.org/spa/resources/documents/misc/treaty-1998-icc-5tdm58.htm

61 Corte Penal Internacional. Documento ICc-01/05-01/08-424. Fiscal c. Jean-Pierre Bemba, Decision Pursuant to Article 61(7)(a) and (b) of the Rome Statute on the Charges of the Prosecutor Against Jean-Pierre Bemba Gombo, Sala de Cuestiones Preliminares II, 15 de junio de 2009. Disponible en: http://www.icc-cpi.int/NR/exeres/269A305D4F4F-4BF0-8F66-9B96B157DDC1.htm, párr. 76. Traducción no oficial. 
porcionada en las poblaciones rurales y pobres, pueblos indígenas, afrocolombianos, sindicalistas, defensores de derechos humanos, y líderes comunitarios"62.

Como se verá más adelante, al tratar los perfiles de las víctimas de los casos de falsos positivos, ellas entran sin duda en la categoría de miembros de poblaciones rurales y pobres. La doctrina de seguridad nacional que sustenta la política de seguridad democrática, que a su vez respalda las ejecuciones extrajudiciales objeto de este informe, propicia la noción del enemigo interno. Este concepto sugiere que son enemigos del Estado y de la sociedad toda persona u organización que asuman posturas democráticas, críticas y diferentes a las del modelo que se quiere imponer desde el poder ${ }^{63}$.

Las medidas que se tomaron a partir del año 2002 en el marco de la política de seguridad democrática otorgaban una serie de facultades a las Fuerzas Militares, con el fin de dirigir la lucha antiterrorista o la lucha contrainsurgente, basadas en la idea de quitarle el agua al pez. De acuerdo con ese planteamiento, la principal ventaja militar de los grupos subversivos eran los vínculos que supuestamente mantenían con la población civil y que adoptaban la forma de complicidad u ocultamiento. En consecuencia, uno de los principales objetivos de las acciones militares emprendidas en el marco de la política de seguridad democrática fue el aislamiento de esos grupos, cuyo principal soporte de acción, de acuerdo con el Gobierno, era "la mimetización de sus integrantes dentro de la población civil".

De tal forma, la política de seguridad democrática generó un ambiente de sospecha generalizado hacia las personas campesinas, habitantes de las zonas controladas o de tránsito de las guerrillas. Como se expresó, el escenario, junto con la ausencia de presencia habitual del poder estatal, el tipo de población y la insurgencia rodeante, es el propicio para que los agentes de la Fuerza Pública del Estado presenten el abatimiento de falsos insurrectos. En el marco del conflicto colombiano, se ha visto cómo a la población civil de regiones donde opera la guerrilla se le ha asimilado con integrantes de dicha organización, siendo así el objetivo de ataques militares y paramilitares. Todas estas consideraciones permiten concluir que los falsos positivos se dieron como parte de un ataque dirigido contra la población civil.

Política de Estado. El Estado promueve o estimula activamente un ataque de esa índole contra una población civil. Y es que no es solo producto de las motivaciones económicas ofrecidas, ni de los beneficios en el régimen de carrera, sino también de la

62 Declaraciones del profesor Philip Alston, Boletín de Prensa, Bogotá, 18 de junio de 2009. Disponible en: http://www.nacionesunidas.org.co/index.shtml?Apc=i1----$\& s=n \& x=58590$ (último acceso: 4 de mayo de 2012).

63 Entrevista con Liliana Uribe Tirado, miembro de la Corporación Jurídica Libertad, del 26 de abril de 2012, en posesión de la FIDH, supra, nota 52. 
misma coacción generada a través de la política estatal de revelar eficiencia y eficacia en el actuar de la Fuerza Pública, la cual se instituía en cada una de las directivas ministeriales a las que ya aludimos, pues la eficiencia del cuerpo armado del Estado se medía en la cuantificación de capturas y bajas de la delincuencia e insurgencia, parámetro que llevó indefectiblemente a los bochornosos actos puestos al descubierto por organismos internacionales.

En el marco de la lucha contrainsurgente y la evocada política de seguridad democrática, se perfilaron y pusieron en práctica módulos normativos con la capacidad de poner todo el aparato armado legítimo del Estado en pro de ciertos objetivos. Y es que la combinación de esa política acoplada al sistema de recompensas por información, a la progresiva presión por resultados y a la falta de control adecuado nos lleva, precisamente, a razonar que las ejecuciones no pueden ser estimadas como actos insulares, sino que existió un alto grado de organización y coordinación con las políticas gubernamentales.

En la tenue verificación de las tesis imperantes, resulta ineludible concluir que las ejecuciones extrajudiciales, sumarias o arbitrarias (o también llamados falsos positivos) tienen la trascendencia en la tipificación del Estatuto de Roma. Deberemos esperar que las decisiones de la jurisdicción interna contengan la trascendencia penal del caso y evitar el asomo del órgano judicial internacional, que deterioraría aún más la afligida imagen del país.

Jurisdicción penal militar. Juez excepcional. En varias oportunidades, se ha puesto en discusión la competencia del juez penal militar en las investigaciones y sanciones de los falsos positivos, partiendo del ámbito de competencia, no solo derivadas de las cláusulas propias de los respectivos estatutos penales militares, sino también de las condiciones que el artículo 221 constitucional ${ }^{64}$ establece para que la investigación y el juzgamiento de los delitos cometidos por los miembros de la Fuerza Pública sea de conocimiento de la justicia penal militar: (i) que el imputado al ejecutar la conducta ilícita se encuentre en servicio activo; y (ii) que el delito guarde relación con el servicio.

La aplicación del régimen foral militar no se agota, por consiguiente, con que se tenga la calidad de miembro activo de la Fuerza Pública al ejecutar el hecho punible; es necesario, además, que el delito esté sustancialmente vinculado con la actividad militar o policial desarrollada por el sujeto agente.

64 Modificado. Acto Legislativo 2 de 1995, art. 1: De los delitos cometidos por los miembros de la Fuerza Pública en servicio activo, y en relación con el mismo servicio, conocerán las Cortes marciales o Tribunales militares, con arreglo a las prescripciones del Código Penal Militar. Tales cortes o tribunales estarán integrados por miembros de la Fuerza Pública en servicio activo o en retiro. 
La Carta Fundamental de 1886, en su artículo 17065, también había consagrado el fuero penal militar, con la particularidad de que era exclusivo para el personal de tal naturaleza, dejando de lado a los miembros de la Policía Nacional; la razón puede ser obvia, pues para la época no se había constituido el organismo armado de raigambre civil. Tal como habíamos explicado, en 1945 con la Ley 3 se expidió un nuevo código penal militar, que cinco años después fue derogado por los decretos 1125 del 31 de marzo 1950 y 957 del 14 de marzo de 1950. Este fue el primer código penal militar que trajo un título y capítulo sobre delitos por infracciones al DIH. Así se refirió a la perfidia, de trato a los prisioneros de guerra, de la prohibición de ciertas armas. En 1958, con el Decreto 250 se expidió un nuevo código que consagraría la equivalencia, para efectos de juzgamiento, entre los términos "militar o militares" y policía. En 1988, se expidió el Decreto 2550, complementado por el acto administrativo 1562 de 1992.

La Ley 522 de 1999 incorporó aspectos importantes a nivel de Derecho Internacional Humanitario y de Derecho Internacional de Derechos Humanos, abrogando la competencia para estos actos delictuales a la justicia ordinaria. Dicha norma recogería aspectos importantes, que subsistieron en parte con la Ley 1407 de 2010, para definir los delitos relacionados con el servicio como "aquellos cometidos por los miembros de la Fuerza Pública derivados del ejercicio de su función militar o policial que les es propia". Se excluyeron del conocimiento de la justicia penal militar los ilícitos de tortura, genocidio y desaparición forzada; sin existir ninguna causal para que puedan ser investigados y juzgados por dicha justicia especial. Igual directriz se planteó frente a los delitos de lesa humanidad.

Lo anterior permite plantear una inquietud que nos conducirá, además de las respuestas de orden social, a un interrogante de orden estrictamente jurídico que resonará en el ámbito de la responsabilidad patrimonial del agente público y de la institución militar o policial. La asignación de la investigación de las conductas atroces de que trata el Código Penal Militar tiene unas motivaciones muy particulares. A pesar de que el canon 221 superior delinea de manera diáfana la asignación para esta jurisdicción, se suma un particular escenario: el alto grado de desconfianza que ha generado la justicia penal militar en varias oportunidades, hecha pública en sendos informes de la CIDH, producto de la ineficiencia e inefectividad de dicha justicia. Tanto la CIDH como la Corte Interamericana de Derechos Humanos, en varias de sus sentencias,

65 Y es que el artículo 166 señalaba: “La Nación tendrá para su defensa un Ejército permanente. La ley determinará el sistema de reemplazos del Ejército, así como los ascensos, derechos y obligaciones de los militares". Por su parte el artículo 170 indicaba: "De los delitos cometidos por los militares en servicio activo y en relación con el mismo servicio, conocerán las Cortes marciales o Tribunales militares, con arreglo a las prescripciones del Código Penal Militar". 
opiniones consultivas y resoluciones de admisión sobre los eventos de supuestas violaciones a los derechos humanos, dejan entrever recelo frente a la imparcialidad de la jurisdicción penal militar. Para la CIDH, la jurisdicción militar no constituye un foro apropiado y por lo tanto no manifiesta un medio conveniente para investigar, juzgar y sancionar violaciones a los derechos humanos consagrados en la Convención Americana, presuntamente cometidas por miembros de la Fuerza Pública o con su colaboración o aquiescencia, sumado a que los familiares de las víctimas se han visto privados de acceder a un recurso adecuado para la investigación, juzgamiento y sanción de los responsables de los graves hechos denunciados.

Una investigación penal debe realizarse prontamente para proteger los intereses de las víctimas, preservar la prueba e incluso salvaguardar los derechos de toda persona que en el contexto de la investigación sea considerada sospechosa. Un antecedente reciente advierte con claridad que la justicia colombiana ha otorgado tratamiento tenue y frágil a estos hechos, como lo han sostenido la Comisión y la Corte Interamericana de Derechos Humanos, y termina menoscabando las prerrogativas de las víctimas. Un asunto confeso de "falsos positivos" fue tratado como un delito de "encubrimiento por favorecimiento"66, a pesar de la insistencia jurídica-procesal del representante del Ministerio Público en lograr variar la conducta por la que fueron juzgados los militares involucrados; a su vez, la Corte Suprema de Justicia en su Sala de Casación Penal se sostuvo en la posición que los jueces de primera y segunda instancia expresaron en un caso, que como lo entendió el procurador delegado, resultaba de trascendencia y gran connotación social67. Explicó la corporación:

Sin vocación de éxito el reparo, tampoco puede entenderse franqueada la posibilidad de la casación oficiosa que propone el demandante so pretexto de que se trata de un caso de trascendencia, connotación y gravedad, porque aunque la Corte no desconoce estos elementos en tan lamentable hecho, lo cierto es que de lege lata tal mecanismo solo es procedente cuando se encuentre demostrada alguna situación de

66 Sentencia del 26 de septiembre de 2012. Expediente 32.636. Magistrado ponente: Luis Guillermo Salazar Otero. Aprobado: Acta 357. Sindicado: Gelver Eduardo Muñoz Montilla.

67 Razonó el procurador, "permitir que un caso de esta trascendencia, connotación y gravedad quede finalmente impune y la abierta vulneración a los derechos y garantías fundamentales aquí quebrantadas permita salir airoso a un condenado que participando en la ejecución extrajudicial de dos seres humanos, ha recibido una condena ilegal por un punible de baja categoría, pues ilegalmente y sin saber por qué le erigieron en encubridor de unos crímenes de los que fue simple y llanamente autor, cuando menos cómplice". 
nulidad, o una ostensible afrenta a las garantías fundamentales, que acá en verdad no se aprecia en esa condición dada la dialéctica que en este asunto tuvo el tema probatorio ${ }^{68}$.

Frente a la decisión se presentó disidencia, apoyada en semejantes consideraciones del censor, por la magistrada María del Rosario González Muñoz, quien recordó que

[...] es precisamente en asuntos como este en los cuales debe tener en cuenta la especial condición de Muñoz Montilla, dado que no se trata de un simple ciudadano, sino de un cabo primero del Ejército colombiano, es decir, de una autoridad cuyas misiones constitucionales y legales son diversas a las de un particular. En efecto, si de acuerdo con el artículo 2 de la Carta Política las autoridades están instituidas para proteger a las personas en su vida y otros bienes, motivo por el cual es incuestionable que tienen posición de garante por institución, no se aviene con tal comprensión constitucional que si un militar tiene conocimiento previo de la futura comisión de 'bajas' en un escenario manifiestamente ilegal, su silencio sobre el particular se adecue simple y llanamente al delito de favorecimiento.

68 Congreso de la República de Colombia. LEY 599 DE 2000. Por la cual se expide el Código Penal. 24 de julio de 2000. Do N. ${ }^{\circ}$ 44.097. Artículo 446, señala: "El que tenga conocimiento de la comisión de la conducta punible, y sin concierto previo, ayudare a eludir la acción de la autoridad o a entorpecer la investigación correspondiente, incurrirá en prisión de dieciséis (16) a setenta y dos (72) meses. Si la conducta se realiza respecto a los delitos de genocidio, desaparición forzada, tortura, desplazamiento forzado, homicidio, extorsión, enriquecimiento ilícito, secuestro extorsivo, tráfico de drogas, estupefacientes o sustancias psicotrópicas, la pena será de sesenta y cuatro (64) a doscientos dieciséis (216) meses de prisión. Si se tratare de contravención se impondrá multa". En el caso particular, los antecedentes nos muestran que en el año 2007, el sindicado Muñoz Montilla confesó haber conocido de la planeación de un operativo ocurrido el 25 de mayo de 2004 y el posterior montaje mediante el cual dos jóvenes del corregimiento San Cristóbal de la capital antioqueña, Arley de Jesús Vallejo Cardona y Yon Fredy García Carmona, fueron presentados como milicianos de las Farc muertos en combate. En los hechos participaron también miembros de la Agrupación de las Fuerzas Especiales Urbanas (AFEUR) del Ejército Nacional, quienes recibieron recompensa en dinero por el "positivo". Gelver Muñoz se acogió a sentencia anticipada y a comienzos de 2008 fue condenado por el Juzgado Cuarto Penal del Circuito a dos años de cárcel por el delito de encubrimiento por favorecimiento agravado, decisión que fue apelada por el agente del Ministerio Público en el proceso, y que fue confirmada por el Tribunal Superior de Medellín en noviembre de ese mismo año. 
La decisión de la corporación convalida la impunidad; "cierra los mecanismos en la justicia interna, convalida la impunidad al desconocer el carácter sistemático de las ejecuciones extrajudiciales y rompe el Código Penal, pues aplica responsabilidad por encubrimiento a quien conocía con anterioridad que el crimen sería cometido"69.

Es deplorable para el Estado de Derecho y la justicia, [...] grave retroceso, porque la justicia en vez de avanzar con paso seguro a reprimir el terrorismo de Estado, parece alegrarse con tejer dudosas fórmulas que ampararán a los militares que usen el poder para delinquir. Le esperan días aciagos en materia de derechos humanos al país, [...] Esa postura apunta a desvirtuar el concepto de delitos de sistema, como lo fueron los falsos positivos, que obedecieron a una idea permanente y organizada de aniquilar inocentes para inflar resultados en la lucha contra la insurgencia. Al considerar que los militares fueron simples encubridores, se desnaturaliza el criterio de crímenes sistemáticos que revistieron los falsos positivos, que se idearon y perpetraron en función de una idea criminal de aniquilamiento de un grupo de personas de la población civil.70

El terrorismo no puede estar marcado únicamente por las actuaciones de grupos insurgentes, o grupos al margen de la ley; el Estado genera terrorismo cuando de manera reiterada, sistemática y valiéndose del ciudadano indefenso, se hace a medios ilegítimos para alcanzar sus objetivos, como lo muestran las realidades jurídicas de las ejecuciones extrajudiciales.

Responsabilidad disciplinaria. El derecho disciplinario puede concebirse como la forma jurídica de regular el servicio público, entendido como la organización política y de servicio, y el comportamiento disciplinario del servidor público. Establece los derechos, deberes, obligaciones, mandatos, prohibiciones, inhabilidades e incompatibilidades, así como las sanciones y procedimientos, respecto a quienes ocupan cargos públicos. El derecho disciplinario constituye un derecho-deber que comprende el conjunto de normas, sustanciales y procedimentales, en virtud de las cuales el Estado asegura la obediencia, la disciplina y el comportamiento ético, la moralidad y la eficiencia de los servidores públicos, con miras a garantizar el buen funcionamiento de los diferentes servicios a su cargo. Su finalidad, en consecuencia, es la de

69 Jorge Molano es representante de víctimas de "falsos positivos". Disponible en: http:// www.derechos.org/nizkor/colombia/doc/falsos33.html

70 La Sala de Casación Penal confirma la condena de Gelver Eduardo Muñoz Montilla a 2 años de prisión por el delito de encubrimiento de falsos positivos. EQUIPO NIZKOR. Disponible en: http://www.derechos.org/nizkor/colombia/doc/falsos33.html 
salvaguardar la obediencia, la disciplina, la rectitud y la eficiencia de los servidores públicos, y allí es en donde se encuentra el fundamento para la responsabilidad disciplinaria, la cual supone la inobservancia de los deberes funcionales de los servidores públicos o de los particulares que ejercen funciones públicas, en los términos previstos en la Constitución, las leyes y los reglamentos que resulten aplicables ${ }^{71}$.

La Constitución prevé la existencia de regímenes disciplinarios especiales, atendiendo a la naturaleza de los órganos del Estado y a las funciones que cumplen; tal es el caso de los miembros de la Fuerza Pública ${ }^{72}$. La estipulación de un estatuto disciplinario específico para los miembros de la Fuerza Pública se explica en razón de las funciones exclusivas que les han sido fijadas. Las diferencia entre los estatutos disciplinarios de las Fuerzas Militares y la Policía Nacional y los aplicables a los demás funcionarios públicos radica en los talantes sustanciales -las faltas en que pueden incurrir y las sanciones que le son aplicables - y no en los procedimentales.

La imputabilidad. Concepción. El Consejo de Estado ha entendido que la simple calidad de funcionario público que ostente el autor del hecho no vincula necesariamente al Estado, pues dicho funcionario puede actuar dentro de órbita privada ajeno o desligado completamente a la función pública que ejerce. Para determinar cuándo el hecho tiene o no vínculo con el servicio, se debe examinar la situación concreta para establecer si el funcionario actuó frente a la víctima prevalido de su condición de autoridad pública, es decir que lo que importa examinar no es la intencionalidad del sujeto, su motivación interna, sino la exteriorización de su comportamiento. En otros términos, lo que importa para atribuir al Estado, por ejemplo, el hecho de agresión de un policía contra un civil es establecer "si a los ojos de la víctima aquel comportamiento lesivo del policía nacional aparecía como derivado de un poder público, siquiera en la vertiente del funcionamiento anormal de un servicio público" 73.

La alta corporación ha referido que las actuaciones de los funcionarios solo comprometen el patrimonio de las entidades públicas cuando estas tienen algún nexo o vínculo con el servicio público. El mero atributo de funcionario público que revele el autor del hecho no vincula imperiosamente al Estado, pues dicho

71 Corte Constitucional de Colombia. SENTENCIA C-030 de 2012. (M.P. Luis Ernesto Vargas Silva; 1 de febrero de 2012).

72 "Artículo 217. Estructura, finalidad y régimen interno de las Fuerzas Militares. [...] La ley determinará el sistema de reemplazos en las fuerzas militares, así como los ascensos, derechos y obligaciones de sus miembros y el régimen especial de carrera, prestacional y disciplinario que le es propio. Artículo 218. Definición, finalidad y régimen interno de la Policía Nacional. [...] La ley determinará su régimen carrera, prestacional y disciplinario".

73 Consejo de Estado, Sala de lo Contencioso Administrativo, Sección Tercera. Sentencia del 26 de septiembre de 2002. Expediente 14.036. 
funcionario puede proceder dentro de suámbito privado, separado por completo de toda actividad pública.

En relación con la conexión o vínculo existente entre la conducta del agente estatal y el servicio público, el Consejo de Estado ha puntualizado que:

[...] las actuaciones de los funcionarios solo comprometen el patrimonio de las entidades públicas cuando las mismas tienen algún nexo o vínculo con el servicio público y que la simple calidad de funcionario público que ostente el autor del hecho no vincula necesariamente al Estado, pues dicho funcionario puede actuar dentro de su ámbito privado separado por completo de toda actividad pública. [...] En doctrina que la Sala ha acogido en reiterada jurisprudencia, se señala que para que la conducta causante del daño, desplegada por un agente estatal, tenga vínculo con el servicio, se requiere que esta se presente externamente como expresión o consecuencia del funcionamiento del servicio público.$^{74}$

En Colombia, se han compartido las premisas delineadas por la jurisprudencia española al aceptar la existencia de la obligación de reparar el daño causado por un agente estatal cuando ha sido resultado de la relación de ocasionalidad con el servicio. Es decir, una mera relación material o fáctica que los conecta o vincula, en cuanto de no encontrarse el funcionario en la administración estatal no se hubiese dado el evento dañoso.

El daño es imputable a la administración pública, puesto que existe ocasionalidad necesaria entre el servicio y el comportamiento del agente público. En otros términos, se presenta este criterio de imputación fáctica en aquellos eventos en los cuales el servicio y las circunstancias que lo rodean hayan sido útiles para la materialización del daño, puesto que bien interna o externamente la conducta del agente no se desliga de la función pública, en cuanto aquella le sirve como motivación o facilita la producción del perjuicio. ${ }^{75}$

74 Consejo de Estado, Sala de lo Contencioso Administrativo, Sección Tercera. Sentencia del 16 de julio de 2008. Expediente 17.124. Consejera ponente: Ruth Stella Correa Palacio.

75 Salvamento de voto. Consejo de Estado, Sección Tercera. Sentencia del 21 de julio de 2009. Consejero ponente: Myriam Guerrero de Escobar. Expediente 4700123310002001101270 01. Actor: Elizabeth Sanjuán Carreño y otros. Demandado: Nación-Ministerio de Defensa-Policía Nacional. 
El funcionario, en el compendio de su relación de servicio, tiene deberes frente a los destinatarios de las labores que realiza en el marco de sus competencias. Es en este momento que aplican esos factores subjetivos como el dolo o la culpa grave, los cuales además habrán de ser significativos en el juicio de prorrateo o distribución de responsabilidad ${ }^{76}$ frente a terceros y ante la Administración.

No obstante la posición reiterada y unánime de esta jurisdicción, la propuesta académica de esta investigación lleva a cuestionar la repetida posición de la jurisdicción contenciosa administrativa:

La noción del artículo 90 no reflejó claridad77 del alcance del concepto de la "imputabilidad", dejándose en manos de la interpretación judicial la edificación de la figura. Fíjense que en la ponencia para primer debate ante la Asamblea Nacional Constituyente se expresó: "Por lo que hace la imputabilidad, se trata de resaltar la circunstancia de que para que proceda la responsabilidad en cuestión, no basta con la mera relación de causalidad entre el daño y la acción de una autoridad pública, sino que es necesario, además, que puede atribuirse al órgano o al Estado el deber jurídico de indemnizarlo. La determinación de las condiciones necesarias para el efecto, quedará naturalmente, en manos de la ley y la jurisprudencia".78

Lo anterior ha permitido que sean la doctrina y el precedente judicial los autores de los rasgos teóricos del concepto y la estructura del concepto.

La última línea de la ponencia adquirió relevancia judicial. La labor del juez administrativo, con la entrada en vigor de la Carta Política de 1991, se propuso fijar los alcances de la imputabilidad y así se hizo, construyendo una tesis que no ha sufrido variación alguna: "Saber si el agente ha actuado con ocasión de sus funciones o si, en cambio, su actividad es puramente personal, privada, exige considerar los parámetros

76 Constitución Política de Colombia. Artículo 90 inciso 2; Ley 270 de 1996, artículos 65 inciso 1, 72; Ley 678 de 2001; Ley 1437 de 2011, artículo 140.

77 "Por lo anterior puede afirmarse que el artículo 90 de la C.P. es tautológico. En su primera parte se recoge lo expuesto, cuando señala: "El Estado responderá patrimonialmente por los daños antijurídicos que le sean imputables [...]", hasta allí la norma contempla los tres elementos de la responsabilidad patrimonial: daño antijurídico, imputación y deber de reparar. La segunda parte de la norma se refiere a "causados por la acción u omisión de las autoridades públicas", esto constituye ni más ni menos la imputación como ya se vio y deviene en innecesario, originando motivos de confusión". Enrique Gil Botero. TEMAS DE RESPONSABILIDAD EXTRACONTRACTUAL DEL ESTADO. 2. ${ }^{a}$ edición. Librería Jurídica Sánchez R. (2001). Pág. 25.

78 Corte Constitucional de Colombia. Gaceta Constitucional N. ${ }^{\circ} 56$ del 22 de abril de 1991. 
más arriba enumerados (tiempo y lugar de comisión de la conducta, etc.), siendo la jurisprudencia [...] quien debe tener la última palabra"79. Así mismo: "Es evidente que la ciencia jurídica no aspira a dar una explicación causal de los hechos y que en las proposiciones que la ciencia jurídica utiliza para describir su objeto se aplica el principio de la imputación y no el de la causalidad"80.

La imputabilidad jurídica es una figura jurídica que debe estar atribuida al cumplimiento de la función constitucional y legal asignada a la fuerza, es decir, como lo han sostenido los pronunciamientos de la Corte Constitucional, la Sala de Casación Penal de la Corte Suprema de Justicia y el mismo Consejo Superior de la Judicatura, a lo que se ha denominado como el acto que guarda relación con el servicio. Una ilicitud que se desenvuelve bajo los parámetros de la ocasionalidad del servicio o por razón de la misma no envuelve el desarrollo de la función y misión constitucional, pues la intencionalidad del agente marca con relevancia e incidencia profunda el acto que ejecuta.

La imputabilidad, como elemento de responsabilidad patrimonial del Estado, según la tesis que propone este trabajo investigativo, tiene que ser entendida bajo los alcances de otros contenidos constitucionales, como los artículos 95-1, 122, 123 inciso 2, 209, 217, 218 y 221, y que se explica así:

La autoridad del Estado se manifiesta por medio de la competencia abrogada a las instituciones y a los funcionarios que lo representan, pero esa prerrogativa tiene por objetivo central cumplir los fines propios del Estado Social de Derecho. Los cometidos estatales se cumplen a través de las actividades oficiales de la administración pública y esas labores deben tener por propósito esos fines u objetivos de la filosofía política del Estado, obligatoriamente el ejercicio de la función pública o de la autoridad deben estar intrínsecamente emparentado a los fines o funciones propias del Estado.

Las condiciones y criterios para la significación de "la imputabilidad" de que trata el artículo 90 de la Carta, ha quedado al desarrollo jurisprudencial, doctrinal, como así se propusieron en los debates ante la Asamblea Nacional Constituyente al explicar la razón de ser de la consagración de la cláusula general de responsabilidad del Estado, una interpretación de otros contenidos normativos superiores permiten concluir que la atribución jurídica al Estado debe estar condicionada que la actuación del agente o servidor solo pueda ser relacionada con el cumplimiento de los fines y cometidos estatales. Cuando el acto, a pesar de su exteriorización, parece fungir con el servicio pero la realidad probatoria termina demostrando que no guarda relación

79 Oriol Mir Puigpelat. LA RESPONSABILIDAD PATRIMONIAL DE LA ADMINISTRACIÓN SANITARIA. Editorial Civitas. (2009). Pág. 215.

80 Hans Kelsen. QuÉ ES JusticıA. Editorial Ariel. (1953). Pág. 225. 
con el fin estatal, sino que se aprovecha el uso de un poder o de una atribución la imputabilidad jurídica debe desdibujarse, pues la intención del representante del Estado jamás evidenció resquicio del cumplimiento de su función pública. Esta terminología no es parte de un juego de semántica, pues son conceptos que para el derecho público, administrativo específicamente guardan una concepción diferente, "si el poder es autoridad, aptitud de mando, y cometido es la tarea o actividad sobre la cual se ejerce el poder, en cambio las funciones estatales son las formas que asuma la actividad estatal para la realización de aquellos cometidos. Así como hay una relación de medio a fin entre el cometido y el poder, la misma relación se presenta entre la función y el cometido" ${ }^{81}$. Las ejecuciones extrajudiciales, no comportan el cumplimiento de una función estatal, aunque sí el abuso de un poder o de autoridad. Obrar conforme a la Constitución, la ley y el reglamento involucra actuar en el servicio, esto es, que la acción debe estar necesariamente en relación con la función u oficio propio que la Carta Política sitúa a cada entidad y a cada funcionario. El servidor público actúa como tal solo cuando está en ejercicio de funciones, sino además, cuando la actividad por él realizada se atempera al objeto propio de la labor funcional asignada a la institución o tiene relación con ella, implica el desarrollo de los fines o cometidos superiores y legales de la institución, o que se desglosa de la función inherente al funcionario. La acción de la Fuerza Pública debe tener como punto de partida la finalidad que la Constitución le entrega a la institución militar o policial, según las previsiones del artículo 217 y 218 de la Carta Magna, defender la soberanía, la integridad territorial nacional y el orden constitucional en un caso, mantenimiento de las condiciones necesarias para el ejercicio de los derechos y libertades públicas y el aseguramiento de la convivencia pacífica.

La imputación de responsabilidad a la Administración requiere en todo caso que la actuación lesiva de la persona autora material de este pueda calificarse como propia del 'funcionamiento de los servicios públicos'. pero no suponiendo la manifestación del desempeño o ejercicio del cargo público, sino de la comprobación real del evento, sabiendo si fue o no producto de la omisión o del exceso en el ejercicio de la función constitucional y legal, pues, probado que no cumplía la función, a pesar de valerse de los elementos que la administración pública ha proporcionado el Estado no podrá resultar comprometida frente a un acto que no implica en esencia y filosofía el cumplimiento de sus cometidos, pues estaríamos así nuevamente frente a tesis

81 Gustavo Humberto Rodríguez. DERECHo AdMINISTRATIVo. TEORÍA GENERAL. TOMO I. Ediciones Librería del Profesional. (1981). Pág. 22. 
antiquísimas y que justificaba a la responsabilidad civil, como la culpa en la elección o culpa en la vigilancia ${ }^{82}$.

La responsabilidad patrimonial del Estado se presenta como un mecanismo de protección de los administrados frente al aumento de la actividad del poder público, el cual puede ocasionar daños que son resultado normal y legítimo de la propia actividad pública al margen de cualquier conducta culposa o ilícita de las autoridades, por lo cual se requiere una mayor garantía jurídica a la órbita patrimonial de los particulares $^{83}$. Pero esto no implica abrogar obligaciones al Estado o atribuirle jurídicamente los resultados de los comportamientos irregulares de sus agentes que no devienen en el desenvolvimiento de la finalidad estatal.

El vínculo y el nexo con el servicio, como es propuesta de esta reflexión, requiere una connotación diferente, si se quiere más estricta. El puente de conexión entre daño antijurídico y acción de la Fuerza Pública solo podrá ser atribuido en la medida en que el actuar del agente público implique, tanto externa como internamente, el desarrollo de las competencias o el ejercicio del servicio público. Cualquier otro acto que de manera volitiva no esté ligado al desarrollo de las potestades públicas, aunque sirvan de telón frente al administrado, no puede obligar a la entidad a asumir cargas patrimoniales.

Los párrafos anteriores revelaron que no se trata de generar irresponsabilidad del Estado, sino que presenta una posibilidad de rediseñar el significado de la imputabilidad, a las luces de otras premisas superiores, sin que conlleve el desconocimiento de la función de garante que cumple el ente público. Otras medidas podrán adoptarse, sin inmiscuir patrimonialmente a la institución, que mantendrían intacta y enaltecerían la labor garantista de la unidad estatal, en especial garantizando la reparación integral (restitutio in integrum) a las víctimas, con la inclusión de medidas de satisfacción o de no repetición por cuenta de los miembros de la Fuerza Pública involucrados.

La Convención Americana de Derechos Humanos impone a los Estados partes el deber de prevenir e investigar las violaciones de los derechos humanos y el deber

82 Teorías que explicaban la razón de ser de la responsabilidad extracontractual por el hecho ajeno. Surge esta obligación cuando entre el autor material del hecho y el que queda responsable hay un vínculo tal que la ley puede presumir fundadamente que si hubo daño, este debe atribuirse, más que al autor material, al descuido o defecto de vigilancia de la otra persona. El fundamento de esta responsabilidad es la presunción de la culpa, que puede consistir en una falta de vigilancia ("culpa in vigilando") o en una desacertada elección ("culpa in eligendo").

83 Corte Constitucional de Colombia. SENTENCIA C-333 de 1996. (M.P. Alejandro Martínez Caballero; 1 de agosto de 1996). 
de identificar y sancionar a sus autores y encubridores ${ }^{84}$. Es decir, toda violación de derechos humanos conlleva el deber del Estado de realizar una investigación efectiva para individualizar a las personas responsables de las violaciones y, en su caso, sancionarlas. Esa labor es parte de la función de garante que se debe cumplir.

La obligación de reparar el daño por la violación de los derechos, como ha insistido la Corte Interamericana de Derechos Humanos, tiene como título el incumplimiento que el Estado hace de su posición de garante, lo que configura el daño antijurídico ${ }^{85}$. Pero de crearse mecanismos que permitan que su agente asegure el resarcimiento pecuniario y no pecuniario ante la eventualidad de las ejecuciones sumarias, sin comprometer el patrimonio de la institución y sin que necesariamente el deber indemnizatorio recaiga sobre el Estado, no desdibuja el papel de garante que engendra, ya que sin duda alguna esta es la circunstancia constitucional determinante que ha marcado los derroteros para el significado de la figura de la imputabilidad introducida en el artículo 90 de la Carta.

\section{CONCLUSIONES}

La responsabilidad patrimonial de la administración pública ha instituido en Colombia un asunto jurídico sobre el cual, aunque se ha iniciado un proceso de depuración, no se tiene un nivel de seguridad jurídica aceptable que nos permita colegir el delineamiento de fuerza con respecto a las distintas tendencias en nuestro medio jurídico.

En las controversias sobre responsabilidad extracontractual del Estado, materia en la cual si bien existen algunas normas generales consagradas en la legislación positiva (tales como el artículo 90 de la Constitución Política que de manera abstracta sirve de fundamento jurídico a la responsabilidad del Estado), lo cierto es que no existe un régimen legal positivo que regule de una manera precisa y detallada dicho tema, lo que hace que el juez pueda encontrar fundamentos de derecho que den giro a diferentes a posiciones que al respecto se han elaborado.

En el orden disciplinario, se hace imperioso ajustar los respectivos estatutos con sanciones adecuadas para las faltas constitutivas de falsos positivos o ejecuciones

84 Corte Interamericana de Derechos Humanos. Sentencia Caso del Caracazo vs. Venezuela, del 11 de noviembre de 1999. Reparaciones, párr. 115; Sentencia Caso Trujillo Oroza vs. Bolivia, del 26 de enero de 2000. Reparaciones, párr. 99; y Sentencia Caso Bámaca Velásquez vs. Guatemala, del 22 de febrero de 2002. Reparaciones, párr. 75.

85 Corte Interamericana de Derechos Humanos. Voto razonado concurrente del juez ad. hoc. Gustavo Zafra Roldán. Ver: Sentencia Caso Mapiripán vs. Colombia. 
extrajudiciales, bien sea genocidios, torturas, homicidios en persona protegida, o en los denominados crímenes de lesa humanidad.

El tratamiento penal a los imputados de los falsos positivos debe ser considerado por los estamentos judiciales como delitos de lesa humanidad, cuyo juzgamiento pueda lograrse por la Corte Penal Internacional.

En los falsos positivos o ejecuciones extrajudiciales, la declaratoria de responsabilidad de las instituciones públicas es el resultado del incumplimiento a la función de garante a que está obligado el Estado, es decir que la imposición resarcitoria funge de la inobservancia del artículo 2 constitucional.

El Estado como ente garante, que se deriva de los artículos 2 y 6, constituye un argumento jurídico autónomo frente al debate de responsabilidad patrimonial en los sucesos de ejecuciones extrajudiciales, el cual se justifica en un modelo de Estado social de derecho donde el individuo-víctima se convierte en el actor principal.

La jurisprudencia del Consejo de Estado ha matizado la figura de imputabilidad jurídica tratándose de la responsabilidad patrimonial de las entidades públicas, en el que la atribución solo es enjuiciada por lo que se exterioriza o evidencia, sin interesar el aspecto volitivo del acto del agente público, es decir que termina involucrando actos que no propenden en nada al cumplimiento de las finalidades constitucionales y legales. La situación de autoridad y la apariencia de su ejercicio bastan, según la alta corporación, para desembocar en el deber institucional de reparar el daño, derivado además de la posición de garante que se predica de los integrantes de la Fuerza Pública, quienes están constreñidos a que sus gestiones: i) se contraigan a los axiomas del Estado de derecho; ii) respeten y hagan respetar los derechos constitucionales fundamentales, los derechos humanos y el Derecho Internacional Humanitario; iii) se encaminen a preservar los bienes jurídicos que la Constitución y la ley ponen bajo su salvaguarda o tutela. Es necesario que el Estado genere mecanismos que permitan crear un fondo para recaudar, del personal de la Fuerza Pública, lo necesario para asegurar la reparación del daño causado a los deudos de una víctima de una ejecución sumaria o extrajudicial.

\section{Recomendaciones}

Garantizar el deber ser de un Estado social de derecho requiere personal capacitado, y el desarrollo de la función pública exige que la persona que lo encarna cuente con las actitudes y las aptitudes para desempeñarse cabalmente. El acceso a las diferentes funciones del Estado muestra, en algunos casos, un filtro débil para ciertas funciones, como la legislativa o la de gran parte del ejecutivo, en las que la mera 
condición de ciudadano lo habilita para su desempeño, bajo la permisibilidad que la democracia en algunos casos justifica. La realidad enseña que el ejercicio de la función de seguridad, en gran parte, permite el ingreso de personas sin mayor capacidad y capacitación. Las bases de la Fuerza Pública están asignadas a ciudadanos que suelen percibir esta labor como una de sus pocas posibilidades de un trabajo que les permita sostenerse económicamente, y son escasos quienes acuden por vocación. Pero con vocación o sin ella, el ejercicio de una labor estatal debe estar encomendado a un ciudadano con actitudes para ello, y como todo empleo público deberá tener mayor rigurosidad para acceder.

Así, será importante robustecer el filtro para el acceso a estos cargos, exigiendo mayor preparación académica y presentación de valoraciones psicológicas y físicas que hagan suponer la idoneidad de los protectores del Estado. Un nivel de escolaridad más exigente permitirá considerar un ciudadano con pleno entendimiento de sus actos, y valoraciones psicológicas de mayor rigor demostrarán su afinidad con el objetivo que persigue la función estatal que desea personificar, y si bien es cierto que no existen métodos de medición de la moral y lo ético, estos medios suponen un filtro más severo, con menos riesgo para la sociedad.

Además, será importante y recomendable que la normatividad jurídica vigente imponga la obligatoriedad de un garante a todo miembro de la Fuerza Pública, bien sea un asegurador o cualquier otra modalidad, que permita satisfacer la reparación económica que se deriva de los eventos violentos encausados como ejecuciones extrajudiciales, salvaguardando además la tranquilidad y convivencia de dichas víctimas bajo un sistema de protección especial que se brinda por estamentos públicos de seguridad distinto del implicado.

Según la hipótesis de la investigación, es el servidor público quien deberá responder directamente, sin compromiso estatal, por las consecuencias económicas del suceso delictivo. Por ello, la necesidad de crear un mecanismo que respalde el posible evento bajo la modalidad de garantías y de la creación de un fondo común con aportes de todos los servidores de las Fuerza Pública, que sean obligatorios y proporcionales a los salarios percibidos.

Aunque algunos no gustan del Estado represivo, el ajuste de las medidas correctivas terminan convirtiéndose en mensajes se prevención. Se deberán adecuar las reglamentaciones disciplinarias y penales para hacer más severas las sanciones derivadas de una ejecución extrajudicial, con expresa contemplación de la figura en cada compendio normativo.

Se requerirá voluntad política de todos los estamentos involucrados para hacer efectivas las investigaciones disciplinarias y penales contra miembros de la 
Fuerza Pública comprometidos en estos eventos, con total independencia, como lo precisan los cánones del Derecho Internacional de Derechos Humanos suscrito y ratificado por Colombia. El desacierto del nuevo artículo 221 constitucional tendrá que ser reevaluado, pues admitir mayor participación de la jurisdicción penal militar en la investigación y los juzgamientos de las actuaciones de sus miembros no ha sido visto con tranquilidad por órganos jurisdiccionales internacionales. Recordemos, además, que las recomendaciones de dichas instituciones hacen parte del bloque de constitucionalidad y como tal deben y tienen que acatarse.

\section{REFERENCIAS}

Alberto Valencia Gutiérrez. VIOLENCIA EN COLOMBIA: AÑOS OCHENTA Y REFORMA CONSTITUCIONAL. Editorial Universidad del Valle. (1998).

Antonio Beristain. El delincuente en el Estado Social de Derecho. Editorial Reus. (1971).

Congreso de la República de Colombia. LEY 522 DE 1991. Por la cual se expide el Código Penal Militar. 12 de agosto de 1991. Do N. ${ }^{\circ} 43.665$.

Congreso de la República de Colombia. LeY 599 DE 2000. Por la cual se expide el Código Penal. 24 de julio de 2000. DO N. ${ }^{\circ} 44.097$.

Congreso de la República de Colombia. LEY 1407 DE 2010. Por la cual se expide el Código Penal Militar. 17 de agosto de 2010. Do N. 47.804.

Consejo de Estado, Sala de lo Contencioso Administrativo, Sección Tercera. Sentencia del 22 de noviembre de 1991. Consejero ponente: Julio César Uribe Acosta.

Consejo de Estado, Sala de lo Contencioso Administrativo, Sección Tercera, entre otras. Sentencia del 14 de diciembre de 1993. Consejero ponente: Daniel Suárez Hernández. Expediente 8493. Actor: Segundo Jorge Pantoja Moreno.

Consejo de Estado, Sala de lo Contencioso Administrativo, Sección Tercera. Sentencia del 26 de septiembre de 2002. Expediente 14.036.

Consejo de Estado, Sala de lo Contencioso Administrativo, Sección Tercera. Sentencia del 16 de julio de 2008. Expediente 17.124. Consejera ponente: Ruth Stella Correa Palacio. 
La imputabilidad en la responsabilidad patrimonial del Estado en las denominadas ejecuciones extrajudiciales y la derivada para los agentes públicos

Consejo de Estado, Sección Tercera. Sentencia del 21 de julio de 2009. Consejero ponente: Myriam Guerrero de Escobar. Expediente 4700123310002001101270 01. Actor: Elizabeth Sanjuán Carreño y otros. Demandado: Nación-Ministerio de Defensa-Policía Nacional.

Consejo de Estado, Sala de lo Contencioso Administrativo, Sección Tercera, entre otras. Sentencia del 11 de noviembre de 2009. Consejero ponente: Enrique Gil Botero. Radicación: 05001-23-25-000-1998-02246-01(35529).

Consejo de Estado, Sala de lo Contencioso Administrativo, Sección Tercera. Sentencia del 28 de abril de 2010. Consejera ponente: Ruth Stella Correa Palacio. Radicación 76001-23-31-0001995-01581-01(17201). Actor: Yasmín Millán Dávila y otros. Demandado: Nación-Ministerio de Defensa-Policía Nacional.

Consejo de Estado, Sala de lo Contencioso Administrativo, Sección Tercera. Sentencia del 14 de septiembre de 2011. Consejero ponente: Enrique Gil Botero. Radicación 05001-23-25-0001994-00020-01(19031). Actor: Antonio José Vigoya Giraldo y otros.

Consejo de Estado, Sala de lo Contencioso Administrativo, Sección Tercera, Subsección B. Sentencia del 29 de marzo de 2012, Expediente 21380. Radicación 20001-23-31-000-199900655-01. Consejero ponente: Danilo Rojas Betancourth.

Corte Constitucional de Colombia. Gaceta Constitucional N. ${ }^{\circ} 56$ del 22 de abril de 1991.

Corte Constitucional de Colombia. SentenciA DE C-333 DE 1996. (M.P. Alejandro Martínez Caballero; 1 de agosto de 1996).

Corte Constitucional de Colombia. SentenCIA C-832 DE 2001. (M.P. Rodrigo Escobar Gil; 8 de agosto de 2001).

Corte Constitucional de Colombia. SEnTEnCIA C-254 DE 2003. (M.P. Marco Gerardo Monroy Cabra; 16 de abril de 2003).

Corte Constitucional de Colombia. Sentencia C-370 de 2006. (M.P. Manuel José Cepeda Espinosa, Jaime Córdoba Triviño, Rodrigo Escobar Gil, Marco Gerardo Monroy Cabra, Álvaro Tafur Galvis, Clara Inés Vargas Hernández; 18 de mayo de 2006).

Corte Constitucional de Colombia. Sentencia C-030 de 2012. (M.P. Luis Ernesto Vargas Silva; 1 de febrero de 2012).

Diego Eduardo López Medina y Astrid Liliana Sánchez Mejía. LA ARMONIZACIÓN DEL DERECHO INTERNACIONAL DE LOS DERECHOS hUMANOS CON EL DERECHO PENAL COLOMBIANO. Editorial Universidad Javeriana. (2008). 
Enrique Gil Botero. TEMAS DE RESPONSABILIDAD EXTRACONTRACTUAL DEL ESTADO. 2. a edición. Librería Jurídica Sánchez R. (2001).

Fabián Omar Canda. Responsabilidad penal de los agentes de la administración pública. Ed. Fabián Omar Canda. RESPONSABILIDAD dEL ESTADO Y DEL FUnCIONARIO PúBLICO. Editorial Ciencias de la Administración. (2001).

Gilberto López y Guillermo Rivas Pacheco. Los crímenes de Estado de Álvaro Uribe Vélez. Blog Rebelión. 20 de marzo de 2009. Disponible en: https://rebelion.org/ los-crimenes-de-estado-de-alvaro-uribe-velez/

Gustavo Humberto Rodríguez. Derecho administrativo. Teoría general. Tomo I. Ediciones Librería del Profesional. (1981).

Hans Kelsen. QuÉ ES JUSTICIA. Editorial Ariel. (1953).

Jean Pictet. DeSARRollo y Principios del Derecho InTERnACIOnAl Humanitario. Instituto Henry Dunant. (1986).

Jesús Orlando Gómez López. LA OBEDIENCIA JERÁRQUICA Y LA INVIOLABILIDAD DE LOS DERECHOS HUMANOS. Ediciones Doctrina y Ley. (1998). Pág. 240.

José Antonio Gutiérrez. Los falsos positivos: los horrores de una guerra mediática. ANARKISMO. 11 de octubre de 2008. Disponible en: http://www.anarkismo.net/article/10199

Leonel Calderón Cadavid. LA INIMPUTABILIDAD EN EL DERECHO PENAL Y EN EL PROCEDIMIENTO. Editorial Temis. (1996).

Lizandro Cabrera Suárez. El control de convencionalidad y la protección de los derechos humanos en Colombia. DIxI 19. Junio de 2014. Pág. 53-70. Disponible en: https://doi.org/10.16925/ di.v16i19.732

Lizandro Cabrera Suárez. La paz: mucho más que el final de la guerra. DIXI 23. Abril de 2016. Disponible en: https://doi.org/10.16925/di.v18i23.1289

Lizandro Cabrera Suárez. El desplazamiento en Colombia y sus diversas miradas. DIXI 25. Abril de 2017. Disponible en: https://doi.org/10.16925/di.v19i25.1818

Louis Josserand. DERECHO CIVIL. TOMO II. Bosch. (1950).

Mario Madrid-Malo Garizábal. Ejecuciones extrajudiciales. El CATOLICISmo N. 95.2 de junio de 2005. 
48 La imputabilidad en la responsabilidad patrimonial del Estado en las denominadas ejecuciones extrajudiciales y la derivada para los agentes públicos

Movimiento Nacional de Víctimas de Crímenes de Estado (Movice). LA GUERRA SE MIDE EN LITROS DE SANGRE. FALSOS POSITIVOS, CRÍMENES DE LESA HUMANIDAD: MÁS ALTOS RESPONSABLES EN LA IMPUNIDAD. Federación Internacional de Derechos Humanos. Disponible en: https://www. fidh.org/IMG/pdf/colombie589e.pdf

Observatorio de Paz Integral (OPI). DESAPARICIÓN FORZADA Y EJECUCIONES EXTRAJUDICIALES PRESENTADAS COMO RESULTADOS POSITIVOS EN COMBATE. DEGRADACIÓN DEL CONFLICTO ARMADO COLOMBiano. UnA mirada desde el Magdalena Medio Colombiano. OPI. (2013).

Oriol Mir Puigpelat. LA RESPONSABILIDAD PATRIMONIAL DE LA ADMINISTRACIÓN SANITARIA. Editorial Civitas. (2009).

Organización de las Naciones Unidas. Folleto InFORMATIVO N. 11. EJECUCIONES SUMARIAS O ARBITRARIAS. 1989. Disponible en: www.un.org/es. 